\title{
A PROPÓSITO DE UNAS FECHAS DEL BAJO ARAGÓN: REFLEXIONES SOBRE EL MESOLÍTICO Y EL NEOLÍTICO EN LA CUENCA DEL EBRO
}

\section{ABOUT SOME ARROWS OF THE LOWER ARAGON REGION: SOME THOUGHTS ON THE MESOLITHIC AND NEOLITHIC OF THE EBRO BASIN}

\author{
por \\ IGNACIO BARANDIARÁN Y \\ ANA CAVA
}

RESUMEN Se presentan dataciones C14 y evidencias arqueológicas del Mesolítico-Neolítico antiguo del Bajo Aragón. Se comentan en el contexto general de la cuenca del Ebro. Se establece la seriación de todo ese proceso cultural en cuatro fases: de denticulados, de irrupción masiva de geométricos, de transición (final del Mesolítico) y de neolitización. Se critica la aplicación aquí del "modelo dual" y se opta por explicar la diversidad de los yacimientos por la funcionalidad/estacionalidad de las ocupaciones y territorios.

\begin{abstract}
We present new C14 dates and archaeological evidences of the Mesolítico-Early Neolithic of the Bajo Aragon. They are discussed in the general context of the Ebro basin. The seriation for this cultural process is established in four phases: denticulates, massive irruption of geometrics, transition (Late Mesolithic) and Neolithic. The application of the "dual model" for this area is criticised and we preter to explain the diversity of the archaelogicaal sites on the basis of the functionality/seasonality of the occupations and territories.
\end{abstract}

Palabras claves Mesolítico, Neolítico Antiguo, Península Ibérica, Crítica de los modelos, Especialización de yacimientos.

Key words Mesolithic, Early Neolithic, Iberian Peninsula, Critic of models, Specialisation of sites.

En julio de 1918, L. Pérez Temprado y M. Pallarés localizaron el yacimiento de Botiquería dels Moros, la primera de las estaciones descubiertas en el Bajo Aragón con una secuencia larga del Mesolítico/Neolítico y que hoy sigue siendo uno de los principales referentes para el conocimiento de esa etapa. 
Iniciado en el conocimiento de la arqueología de campo con su abuelo L. Pérez Temprado, Enrique Vallespí empezó su aportación científica a la Prehistoria precisamente en este territorio hace ya cincuenta años. Con la prospección y descripción de un elevado conjunto de yacimientos y materiales de superficie, sentó las bases para la individualización del tramo postpaleolítico en el Bajo Aragón ampliando después sus revisiones de conjuntos similares a otros lugares de la cuenca del Ebro: Aragón, Rioja, Navarra y Álava.

En especial destacaríamos para nuestro provecho ahora su valoración de los conjuntos líticos de superficie de la cuenca del Matarraña, la identificación y excavación de los estratificados de Serdá y Sol de la Piñera o la primera noticia de cerámica cardial procedente del abrigo de Botiquería que fue precisamente, tiempo después, el factor determinante de nuestra excavación en ese sitio y desencadenó la inmediata de Costalena. Otros investigadores ligados a la Universidad de Zaragoza (P. Utrilla, J.M. Rodanés, L. Montes, C. Mazo, T. Andrés...) han continuado trabajando sobre yacimientos y materiales de este territorio, ampliando el conocimiento de su ocupación mesoneolítica.

Hemos compartido con Enrique Vallespí muchas conversaciones y trabajo: participó con nosotros en una parte de la excavación de Costalena de 1975, juntos abordamos el esclarecimiento de las ricas colecciones de superficie de Urbasa, completamos una visión general de la Prehistoria de Navarra y preparamos todavía ahora alguna reflexión crítica sobre el desarrollo de nuestra disciplina. Para nosotros es, además del maestro -fue de hecho profesor de Prehistoria de uno de nosotros (IB)-, que transmite su entusiasta vivencia de esta disciplina y su perspicaz conocimiento de matices tipológicos, un amigo de verdad.

\section{PRESENTACIÓN}

El cuadro de dataciones absolutas sobre el Mesolítico y su secuencia en el Neolítico antiguo, uno de los temas hoy de moda en la Prehistoria peninsular, se ha ido constituyendo hace poco en los territorios de interior de la cuenca del Ebro. Hace más de veinte años se publicó (Barandiarán 1976) la primera datación absoluta del entonces llamado complejo geométrico del Epipaleolítico del ámbito mediterráneo español: la entregó el sitio que acabábamos de excavar de Botiquería dels Moros, uno de los pocos yacimientos entonces bien identificados en el reducido panorama de la cuenca del Ebro. Ahora la última visión de conjunto sobre esas situaciones culturales en este extenso ámbito geográfico (Utrilla, Cava et alii 1998) dispone de casi noventa fechaciones, listado ciertamente amplio y bastante suficiente: proceden de veintiocho yacimientos que representan las diversas zonas mayores de este amplio territorio interior de la Península Ibérica: ocho sitios de Álava y Navarra media, dos de la Navarra prepirenaica, cuatro del Alto Aragón (prepirineo oscense), ocho del Bajo Aragón (en las provincias de Zaragoza y Teruel) además de otros seis de parajes inmediatos (uno de Rioja, otro de Andorra y cuatro de Cataluña). Como es obvio, también está siendo muy notable en los últimos años el incremento de datos objetivos aportados por excavaciones de garantía: es decir, de estratigrafías bien preservadas y de suficientes lotes de industrias y de referencias ambientales.

La oportunidad de presentar ahora seis nuevas dataciones de Botiquería del Moros y Costalena nos anima a recuperar y contrastar resultados analíticos ya publicados sobre el medio y los usos culturales del Mesolítico y Neolítico en el Bajo Aragón y a reflexionar sobre lo mesolítico en el ámbito mayor del conjunto de la cuenca del Ebro y zonas próximas, en cuanto a su caracterización en utillaje y sistemas de subsistencia/asentamiento frente a lo epipaleolítico precedente y al Neolítico 'antiguo'. 


\section{LOS DATOS}

\subsection{Los yacimientos estratificados}

Se ha reconocido en el ámbito bajoaragonés una treintena de localizaciones arqueológicas correspondientes al lapso cultural extendido desde el Epipaleolítico al Neolítico avanzado (y/o Calcolítico). Su núcleo principal, situado en los tramos medio e inferior del río Matarraña con su confluente Algás, se ha visto ampliado con la localización de asentamientos, hacia el oeste, en los valles del Guadalope y del Martín. Veinte de esos sitios habían sido enumerados por E. Vallespí en sinopsis y trabajos de sistematización (Vallespí 1957 y 1959) reuniendo localizaciones debidas en su mayoría a L. Pérez Temprado y excepcionales de J. Cabré y S. Vilaseca, con otras del propio Vallespí; a ellos se añaden en la guía arqueológica de la región (Mazo, Montes, Rodanés y Utrilla 1987) otros cinco. El valor de los datos contenidos en ese repertorio de localizaciones es muy desigual, ya que depende de la entidad del efectivo arqueológico entregado, de su disposición estratificada o "de superficie" y de la definición cronocultural que permiten.

El diagnóstico cultural de la mayoría de esos sitios se sirve de industrias líticas escasas (acompañadas, en algún caso, de restos cerámicos a mano) cuyos caracteres tecnotipológicos tienen en general muy poco valor diagnóstico y habían sido recogidas sin mediar sondeo estratigráfico. Con esos datos se han definido unos cuantos conjuntos líticos de superficie y/o talleres catalogados, a falta de más argumentos, dentro de la Prehistoria reciente (en un impreciso Neolítico/Bronce): destacaremos los de el Cingle de la Boquera (Ribarroja de Ebro), la desembocadura del Matarraña (Fayón), La Planeta, el abrigo de la Noguera, los sitios del Rabinat (El Balcón y El Cabo), los Cinglos de la Muntfalla, el Barranc del Infern y la Val de Envidella (Fabara), La Trapa, el Azud de la Noguera y el Tossal de les Forques (Maella), las Caídas del Salbime, la Punta del Alcañizano y los abrigos de La Horteta, Era de Rayos y La Chesera (Mazaleón) y la Font d'en Oro (Calaceite).

Son diez las localizaciones bien controladas en excavaciones de cierta o mayor precisión que entregaron suficientes datos arqueológicos (industriales, medioambientales y de disposición del yacimiento) estratificados. Por una parte están los sitios 'de aire libre' del Serdá y del Sol de la Piñera (ambos en Fabara) que E. Vallespí excavó en 1956/1957 y publicó de seguido (Vallespí 1960); por otra, las ocupaciones restringidas en el tiempo de la cueva del Llop y del abrigo dels Secans (en término de Mazaleón) excavados, respectivamente, por C. Mazo y L. Montes en 1986 y por J.M. Rodanés en 1986/1987 con un avance la primera (Mazo y Montes 1987) y una memoria definitiva la segunda (Rodanés, Tilo y Ramón 1996). Y, por fin, los abrigos que han conservado las secuencias estratigráficas más amplias en La Botiquería dels Moros (Mazaleón), La Costalena y El Pontet (los dos en Maella) en la cuenca del Matarraña-Algás, el de Ángel (Ladruñán) en la del Guadalope y el de Baños (Ariño) en la del Martín. Han sido excavados los dos primeros por I. Barandiarán y A. Cava en 1974 y 1975, el tercero por C. Mazo y L. Montes en 1986, Ángel por A. Sebastián en 1986-87 y P. Utrilla en 2000 y Baños por P. Utrilla en 2000. Se han publicado las memorias definitivas de las intervenciones en Botiquería y Costalena (Barandiarán 1978; Barandiarán y Cava 1989), sendos avances detallados de Pontet (Mazo y Montes 1992) y Ángel (Sebastián 1988), y referencias puntuales de lo más reciente de Ángel y de los Baños de Ariño (Utrilla 2000); hubo, además, en 1955 y 1959 campañas de excavación en Botiquería por J. Tomás que permanecen, salvo una nota muy escueta (Tomás y Vallespí 1960), prácticamente inéditas. El asentamiento de Alonso Norte (Alcañiz), en la cuenca media del Guadalope, ha sido excavado hace poco y publicado extensamente (Benavente y Andrés 1990).

Las depósitos arqueológicos acumulados en los sitios de referencia (figura 1) ofrecen, simplificadamente y de acuerdo con las memorias y/o avances publicados por sus excavadores, diferentes secuencias.

La excavación de la "estación-taller" de aire libre (de hecho es una extensión de solana adosada a una ladera rocosa) de Sol de la Piñera identificó (Vallespí 1960: 22-27) un único nivel arqueológico (el estrato II, 
de espesor entre 11 y $17 \mathrm{~cm}$ ) con materiales líticos tallados referidos a "una cronología mesolítica" (Vallespí 1959: 312 y 1960: 38) próxima al horizonte cultural definido como 'Cocina II' (Fortea 1973: 399) del Epipaleolítico final de facies geométrica.

El otro "taller" de aire libre protegido del Serdá entregó (Vallespí 1960: 28-36) un solo estrato (depósito II, de algo más de $90 \mathrm{~cm}$ de espesor) bien individualizado entre el suelo (estrato I) y la acumulación posterior estéril (III). La no fácil atribución cultural del efectivo lítico tallado por E. Vallespí a un obvio "fondo epipaleolítico" se decanta (Fortea 1973: 399), al considerarse algunos elementos líticos de más amplio espectro, por el modelo de los horizontes cerámicos de Cocina.

El espesor (100 a 150 cm) acumulado en el abrigo de Botiquería dels Moros se articula (Barandiarán 1978: 65-106) de abajo arriba en ocho unidades de depósito intercalándose niveles de ocupación (2, 4, 6 y 8) con otros estériles (1, de base, 3, 5 y 7). En esos niveles se suceden situaciones consecutivas que cubren desde el Epipaleolítico geométrico (en 2 y 4) al Neolítico antiguo (en 6 y 8 ) .

El abrigo de Costalena conservaba seis horizontes sedimentarios genéricos en una potencia que, según los sitios, va de los 200 a los $250 \mathrm{~cm}$ y donde se suceden (Barandiarán y Cava 1989: 21-77), sobre el nivel e basal y prácticamente estéril, el d de adscripción genérica al Epipaleolítico con pocos geométricos y bastantes piezas denticuladas masivas, el c3 del Mesolítico geométrico pleno, los c2 y c1 del Neolítico antiguo y los b y a, muy superficiales, con intrusiones frecuentes de elementos materiales de la Prehistoria posterior.

El covacho del Llop entregó una estratigrafía de aproximadamente $100 \mathrm{~cm}$ de espesor en que se diferenciaron (Montes y Mazo 1987: 121-128) sobre el nivel estéril de base (nivel e) cuatro niveles de difícil definición: la industria lítica y algunos fragmentos cerámicos del nivel b lo hacen "relacionable con las etapas cerámicas de los vecinos yacimientos de Botiquería (niveles 6, 7 y 8) y Costalena (niveles c1 y c2)... como un Neolítico Antiguo de forma genérica".

En el abrigo del Pontet se acumuló un relleno de unos $170 \mathrm{~cm}$ de potencia media en el que se han distinguido (Mazo y Montes 1992: 244-245) seis unidades de ocupación (i, g, e, c inferior y c superior y b) entre las que se intercalan otras estériles ( $\mathrm{j}, \mathrm{h}, \mathrm{f}$ y d): los niveles i y g, con pocos útiles, representarían una fase pregeométrica; el nivel e un Epipaleolítico geométrico "plenamente configurado"; el nivel c inferior supondría la "transición epipaleolítico-neolítico"; y los c superior y b una evolución del Neolítico antiguo.

El abrigo dels Secans conservó una estratigrafía de cerca de $100 \mathrm{~cm}$ de espesor en que (Rodanés, Tilo y Ramón 1996: 8-31) sobre un nivel III de base se depositó la masa del nivel II cuyos dos subniveles arqueológicamente significativos representarían una continuidad cultural desde una fase avanzada del Epipaleolítico geométrico al que se incorporan elementos materiales propios de la neolitización (Rodanés, Tilo y Ramón 1996: 102-103).

En la estratigrafía del abrigo de Ángel se suceden varias unidades estratigráficas la más antigua de las cuales se remonta al Paleolítico superior (Utrilla 2000). Las fértiles que aquí interesan (Sebastián 1988; Utrilla, Cava et alii 1998: 193) son, de abajo a arriba, las 13 y 8 inferior de aspecto macrolítico, las 8 media y 8 superior del Epipaleolítico geométrico, y las 6 y 11, más recientes, del Neolítico avanzado.

En los Baños de Ariño se han excavado dos niveles epipaleolíticos (Utrilla 2000): de aspecto macrolítico el 1 y de composición geométrica el 2, no habiendo sido por el momento abordados los niveles superiores, 3 y 4.

Finalmente, en el sitio de Alonso Norte-que, aunque en su mayor parte se estructura al aire libre, se adosa a un macizo rocoso que le sirve de protección- se recuperó (Benavente y Andrés 1990) un homogéneo conjunto industrial adscribible a un Neolítico plenamente formado. 


\subsection{Las dataciones de Botiquería dels Moros y de Costalena}

En octubre de 1975, concluidas nuestras campañas de excavación del bienio 1974/1975 en Botiquería dels Moros y Costalena, enviamos sendas muestras para datación C14 a J. Evin del Laboratoire de Radiocarbone de la Universidad Claude Bernard de Lyon: recibimos sus resultados en mayo de 1976. La muestra de carbones de un hogar del nivel 2 de Botiquería entregó la primera datación absoluta (Ly.1198) del complejo geométrico del Epipaleolítico del ámbito mediterráneo peninsular y se publicó inmediatamente (Barandiarán 1976). La fechación de fragmentos óseos de Costalena resultó inviable: "pese a todos nuestros esfuerzos no hemos podido obtener resultado de la muestra de Costalena niv. c3 pues era demasiado pequeña la cantidad de esos huesos, estaban parcialmente quemados y ya no conservaban más materia orgánica (colágeno) por lo que aunque, en general, preferimos efectuar las medidas sobre huesos, pienso que en el caso de este yacimiento sería preferible datar carbones de madera" (J. Evin in litt. 04.05.1976).

Diez años más tarde, preparando la memoria sobre Costalena y para compensar aquel intento fallido de datación de huesos, pretendimos aportar los carbones que sugería J. Evin: tampoco pudimos reunir entre las tierras retenidas del nivel c3 la mínima cantidad necesaria para un análisis radiocarbonométrico convencional pues los hogares incluidos en la estratigrafía del abrigo (evidentes por la acumulación de bloques que los estructuran cercando manchas muy negras de tierra) sólo habían entregado un polvo cenizoso muy fino con partículas mínimas de huesos quemados. Optamos, por ello, por aportar otra nueva muestra de huesos (que en octubre de 1985 confiamos a W.G. Mook del Centrum voor Isotopen Onderzoek de la Universidad de Groningen para datación por C14-convencional) conseguida reuniendo muchos pequeños fragmentos óseos quemados (160 trocitos en total, con un peso conjunto de 95 gr.) procedentes de un área de un metro cuadrado en un tramo de cierto espesor (no más de $30 \mathrm{~cm}$ ); su datación (GrN.14098) comunicada en febrero de 1987 fue publicada en la monografía sobre el yacimiento (Barandiarán y Cava 1989: 126).

Por fin, en 1998, aprovechando las posibilidades de la analítica C14 por acelerador, seleccionamos entre los restos óseos de las campañas de 1974 y 1975 depositados en los Museos de Teruel y Zaragoza seis muestras que se enviaron a J. van der Plicht del Centrum voor Isotopen Onderzoek de Groningen. En abril de 1999 recibimos las fechas correspondientes a los niveles 2, 4, 6 y 8 de Botiquería (respectivamente análisis GrA.13265, 13267, 13268 y 13270) y c3 y c2 de Costalena (GrA.10949 y 13264): hasta ahora estaban inéditas. Los costos de este programa de análisis han sido subvencionados con cargo al proyecto de investigación de la Universidad del País Vasco (UPV.155.130-HA 116/97) sobre "Explotación del medio en el Pleistoceno superior/Holoceno: sitios, equipamiento y paisaje" concedido a los firmantes de este texto. Su buen término sólo ha podido llevarse a cabo gracias a la excelente disponibilidad de los responsables de los museos en que depositamos en su día los materiales de ambos yacimientos: el Dr. Miguel Beltrán (Director) en el Museo de Zaragoza donde están los efectivos de Costalena y don Jaime Vicente Redón (Director) y doña Carmen Escriche Jaime (Conservadora de la Sección de Documentación) en el Museo Provincial de Teruel donde se hallan los de Botiquería dels Moros.

Las seis dataciones C14/AMS (cuatro de Botiquería y dos de Costalena) que ahora presentamos ofrecen, junto a las dos anteriormente conocidas de ambos sitios, un bastante preciso cuadro de referencia cronológica. Las datas se ofrecen en fechas C14 BP y, entre paréntesis, calibradas según el programa Ox. cal. (Stuiver y Reimer 1993).

En Botiquería dels Moros de abajo arriba se han datado:

- el nivel 2 en $7600 \pm 50$ años BP (=6456 a 6386 cal. BC; datación GrA.13265) sobre un fragmento medial de metápodo de ciervo de 8,23 gr. de peso (sector 3 del cuadro 1F en semitalla -178/-173; extraído e inventariado el 29.06.1974 con sigla BM.1F.178.523); 
— el nivel 2 en 7550 200 BP (=6553 a 6166 cal. BC; análisis Ly.1198), datación producida en 1976 (y publicada en Barandiarán 1976) sobre una muestra de carbones de madera contenidos en un hogar del cuadro $1 \mathrm{H}$ (fue excavado y retenidos sus carbones el 25.06.1974).

- el nivel 4 en $6830 \pm 50 \mathrm{BP}$ (=5702 a 5623 cal. BC; análisis GrA.13267) sobre un fragmento de hueso de mamífero de 8,12 gr. de peso (sector 3 del cuadro $1 F$ en semitalla-142/-137; extraído e inventariado el 26.06.1974 con sigla BM.1F.142.548);

— el nivel 6 en $6040 \pm 50$ BP (=4994 a 4900 cal. BC; análisis GrA.13268) sobre un fragmento de hueso de mamífero de 11,99 gr. de peso (sector 2 del cuadro $2 \mathrm{G}$ en semitalla-120/-115; extraído e inventariado el 27.06.1974 con sigla BM.2G.120.69);

— el nivel 8 en $6240 \pm 50 \mathrm{BP}(=5252$ a 5204 cal. BC; análisis GrA.13270) sobre un fragmento de hueso de mamífero de 17,19 gr. de peso (sector 2 del cuadro $1 \mathrm{G}$ en semitalla -95/-90; extraído e inventariado el 21.06.1974 con sigla BM.1G.95.63).

En Costalena se han datado:

— la parte media a alta del nivel c3 en $6310 \pm 170$ años BP (=5384 a 5065 cal. BC; análisis GrA.10949) sobre una muestra muy pequeña (cinco trocitos con peso total de 3,14 gr.) de huesos de mamíferos (procedentes del sector 9 del cuadro 9M en semitallas -408/-404 y -398/-394, extraídos e inventariados el 02.10.1975 con sigla Co.9M.408.2037 a 2040);

— la parte más alta del nivel c3 en 6420 $250 \mathrm{BP}(=5528$ a 5195 cal. BC; análisis GrN.14098) (ya publicada en Barandiarán y Cava 1989.126) sobre una muestra de abundantes pequeñas esquirlas óseas (160 fragmentos con peso total de 95 gr. que proceden de varios sectores del cuadro $9 \mathrm{M}$ en cotas -387/-350 y -374/-338 y fueron extraídos el 01.10.1975);

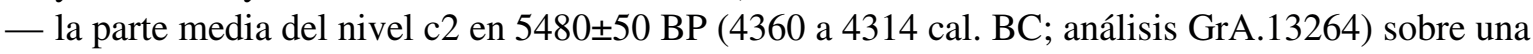
muestra de una docena de trocitos de huesos de mamíferos (de 6,32 gr. de peso; sectores 1, 2 y 3 del cuadro 7O en semitalla -280/-278, extraídos e inventariados el 28.06.1975 con sigla Co.7O.398.408).

Como es habitual, los laboratorios que han producido las dataciones han opinado sobre la significación de las muestras y el valor de sus resultados. En los casos de las dos dataciones por C 14 convencional, tanto el laboratorio de Lyon como el de Groningen que fecharon, respectivamente, la muestra de carbones de Botiquería y de huesos de Costalena (Ly.1198 y GrN.14098) consideraron suficientes las muestras, innecesarias las correcciones de edad y adecuados los resultados. Tampoco crearon problemas al laboratorio de Groningen ni el procesado ni los resultados de los análisis de huesos de Botiquería y Costalena por C14-AMS (GrA.10949, 13264, 13265, 13267, 13268 y 13270), salvo en el caso del nivel c3 de Costalena (GrA.10949) que fue dado con la reserva de que "su muestra era muy pequeña (incluso para AMS)" (J. van der Plicht in litt. 13.04.1999)

Sendos ligeros décalages se advierten entre dataciones de niveles inmediatos: una inversión (6040 50 y 6240 \pm 50 ) en la secuencia de fechas C14-AMS de los niveles 6 y 8 de Botiquería (GrA.13268 y 13270) y otra también reducida (6310 \pm 170 y 6420 250 ) entre las de C14/AMS y C14/convencional de las partes media a alta y más alta del nivel c3 de Costalena (GrA.10949 y GrN.14098). Reconocemos que en ambos casos el lapso de distancia temporal (doscientos años en Botiqueria y poco más de cien en Costalena) que media entre los pares de datas no es excesivo y puede sin excesiva dificultad ser asumido por la oscilación de probabilidad del ámbito de las medidas que, de cierto, resulta bastante amplio $( \pm 170$ y \pm 250$)$ en el caso de Costalena. Más aún recordaremos, para justificar el mínimo desfase en el caso de Costalena, la propia inseguridad del laboratorio sobre la data GrA.10949 (cuya muestra era "muy pequeña") y la composición que hubimos de hacer en la GrN.14098 (por falta de cantidad suficiente de muestra) agrupando numerosas esquirlas menores procedentes de cierta extensión y profundidad del depósito del abrigo. 
No ha sido posible aumentar las dataciones de Costalena, pues no conseguimos localizar en los depósitos del Museo de Zaragoza (pese a la diligencia y colaboración de su Director) alguna de las cajas donde se hallaban parte de los huesos del sitio y que, al parecer, habrían podido quedar traspapeladas con/entre las del depósito de Velilla de Ebro (anexo al Museo capitalino).

Ese lote de fechas de Botiquería dels Moros y de Costalena se completa con diez más (tres del Pontet, una del Llop, tres de Ángel, dos de Los Baños y una de Alonso Norte).

— En el abrigo del Pontet se han datado (Mazo y Montes 1992) el nivel e en 7340 \pm 70 BP (=6214 a 6110 cal. BC) (GrN.16313), el nivel c inferior en 6370 70 BP (=5340 a 5256 cal. BC) (GrN.14241) y el nivel b en $5450 \pm 290$ BP (=4600 a 3961 cal. BC) (GrN.14240).

- El nivel d de la cueva del Llop ha entregado una datación (información personal de C. Mazo) en $4220 \pm 340$ BP (=3337 a 2450 cal. BC) (GrN.14242).

— En Ángel se data (Sebastián 1988) la unidad 13 en $8210 \pm 210$ (=7487 a 6999 cal. BC) y $8150 \pm 70$ BP $(=7258$ a 7168 cal. BC) (GrN.15519 y 15520), y la unidad 8 inferior en $8060 \pm 270$ BP $(=7293$ a 6616 cal. BC) (GrN.15518).

— En los Baños de Ariño el nivel 1 ha entregado la fecha de 7840 \pm 100 BP (=6726 a 6533 cal. BC) (GrN.24299) y el 2 la de 7570 \pm 100 BP (=6461 a 6349 cal. BC) (GrN.24300) (Utrilla 2000).

— Finalmente, el único nivel de ocupación de Alonso Norte se dató en 4600ะ160 BP (=3517 a 3095 cal. BC) (GaK-13877) (Benavente y Andrés 1990).

- Mientras se reconoce imposible la fechación de Secans por "inexistencia de restos susceptibles de ser datados por C14" (Rodanés, Tilo y Ramón 1996: 75) parece que, en lógica, deben ser rechazadas por demasiado jóvenes las dataciones del Llop y de Alonso Norte.

Las dataciones ahora obtenidas en los abrigos de Botiquería y de Costalena permiten confirmar la secuencia ya sugerida por las fechaciones anteriores y, a la vez, aportar algún detalle que nos parece de interés. En resumen, se puede afirmar:

- que la ocupación geométrica más antigua se perfila en un lapso temporal uniforme y, en muchos casos, se instala sobre otra previa de denticulados o macrolitos.

— que la aparición de la cerámica en estas estratigrafías es tardía: no aparece hasta el último tercio del séptimo milenio, y las técnicas de domesticación del medio lo hacen aún más tarde.

- que existe una fase de transición entre lo más propiamente mesolítico y esas primeras cerámicas que, si en algunos abrigos se depositó sin solución de continuidad respecto a las infra y suprayacentes (Costalena) o no pudo datarse (Secans), en Botiquería ha sido perfectamente aislada en su nivel 4. El interés de este conjunto radica en la presencia en él tanto de triángulos de dos lados cóncavos, (parecidos a los de la fase Cocina II) como de triángulos de retoque en doble bisel (de la fase Cocina III), técnica que consideramos indicadora de la neolitización en toda la cuenca del Ebro donde, habitualmente, aparece de modo simultáneo a las cerámicas más antiguas. La datación de $6830 \pm 50 \mathrm{BP}$ supone una alta antigüedad para este nivel 4 de Botiquería que no es demasiado grueso (entre 20 y 6 centímetros según Barandiarán 1978: 82) y, por tanto, para el inicio palpable del proceso de neolitización en el asentamiento. Reivindicamos la fecha como válida por varios motivos:

a) la muestra consistía en un único hueso de mamífero, por lo que deben descartarse resultados híbridos como los que se pueden aducir para muestreos más extendidos;

b) la ocupación de origen se individualizó fácilmente de las anterior y posterior por mediar entre ellas sendos depósitos prácticamente estériles (respectivamente los niveles 3 y 5); y

c) en la memoria de los resultados sólo se consideran como originarios de niveles particulares aquellas piezas que no presentan ninguna duda de adscripción; pues, cuando no se dieron las condiciones 
idóneas de recuperación (en sectores alterados del yacimiento), los materiales se adscriben siempre a niveles genéricos y no se toman en consideración ni en la caracterización cualitativa ni cuantitativa de los lotes claramente diferenciados.

\section{LAS CONSTATACIONES}

Señalamos, de entrada, que los datos hoy disponibles sobre el tiempo y espacio interesados:

— provienen en todos los casos de estratigrafías acumuladas al amparo de viseras o formaciones rocosas;

- se asientan fundamentalmente en las tres secuencias de mayor amplitud cronocultural (Botiquería, Costalena y Pontet) que se completan con los de los otros depósitos estratificados;

- y resultan-como en tantos otros sitios-deficitarios ya que pensamos que la conservación de bastantes de los restos iniciales ha sido muy deficiente, provocando la desaparición de casi todos los de naturaleza orgánica (industrias óseas, fauna, macrorrestos vegetales y, en algunos casos, incluso polen).

Pese a ello, en ese conjunto de datos -heterogéneos y no tantos como se quisiera-se asientan las varias perspectivas de información y el esfuerzo de interpretación con que se esboza un cuadro de situaciones culturales sucedidas desde el Epipaleolítico genérico al Neolítico avanzado. Podemos, con cierta seguridad, empezar a definir la conformación básica de un paisaje, el equipamiento común en utillaje lítico de aquellos grupos y un amplio abanico de recursos de explotación (la caza de especies terrestres, la pesca de peces en los ríos inmediatos a los asentamientos, o la recolección/ utilización de los recursos vegetales del entorno).

\subsection{La evolución industrial y su cronología}

La industria lítica representa, con diferencia, el conjunto de más entidad de lo recuperado: falta la industria ósea y la cerámica es siempre escasa aunque diversa desde el punto de vista decorativo. Por ello la dinámica interna del equipamiento lítico ha servido de base referencial para reconocer situaciones sucesivas que, partiendo de caracterizaciones tecnotipológicas, se han asentado como "fases culturales" diferenciables en los yacimientos en cuestión. En un principio se utilizó como base comparativa la secuencia expuesta por J. Fortea para la cueva de la Cocina (Dos Aguas, Valencia) (Fortea 1971 y 1973): así se advierte especialmente en la contextualización de Botiquería dels Moros, la primera de las estratigrafías espesas cuyo estudio se abordó de forma amplia (Barandiarán 1978). Pronto, la intensificación de la investigación y la riqueza de algunos yacimientos bajoaragoneses permitió ampliar en el tiempo y enriquecer internamente aquel modelo de referencia, a la vez que dotarlo de un elenco coherente de dataciones.

Dejando de lado las conocidas secuencias del Paleolítico medio, se debe apuntar la presencia esporádica de grupos superopaleolíticos que ocuparon distintas cavidades de la región: los Toros de Cantavieja (Utrilla y Álvarez 1985) o un nivel de base del abrigo de Ángel (Utrilla 2000) ambos en la cuenca alta del Guadalope. Sin embargo, la presencia humana continuada en los asentamientos en abrigo o al amparo de bancos rocosos se inicia, en el Holoceno, a partir del noveno milenio BP y se concreta en cinco fases, de más antigua a más moderna, que se completan con el cuadro adjunto de dataciones C14 en años BP de que ahora disponemos (figura 2):

Fase A: se ha dado a conocer reiteradamente en la bibliografía como dotada de conjuntos pertenecientes a un Epipaleolítico genérico, de carácter macrolítico o "campiñoide" (Barandiarán y Cava 1985: 84-85), sin que ninguno de estos términos llegue a convencer a todos. Ofrece una industria escasamente laminar, basada 
en útiles sobre lascas a veces carenadas y relativamente grandes que se utilizan como base para la fabricación de, sobre todo, denticulados y raederas y, en menor medida, de perforadores y de raspadores. En algunos asentamientos se presenta en estado casi exclusivo - unidades 13 y 8 inferior de Ángel, nivel 1 de los Baños-, pero en otros se combina con una débil utilización de elementos laminares -Costalena d-. Los niveles i y $g$ en la base de la secuencia de Pontet, que entregaron pocos materiales, se han atribuido a un estadio "no geométrico" o "con macrolitos". Las dataciones C14 de Ángel y los Baños sitúan esta fase en el Bajo Aragón entre el último tercio del noveno y el primero del octavo milenios BP, según las fechas extremas de $8210 \pm 210$ en aquel sitio y 7840 en éste. Esta solución tecnotipológica, explicable sin duda a través de argumentos de funcionalidad, se prolongará en el tiempo perdurando en situaciones cronológicas y culturales posteriores.

Fase B: se caracteriza por una introducción masiva de utensilios geométricos obtenidos a través de una tecnología laminar depurada y notablemente estandarizada. En este momento son preferentes los trapecios de retoque abrupto que utilizan la técnica del microburil de forma masiva como técnica para fracturar los soportes, esbozando ya la oblicuidad de las truncaduras que conformarán estos geométricos. Los "típicos" niveles de esta fase son: el 2 de Botiquería, la mayor parte del c 3 de Costalena, el e de Pontet, los 8 medio y superior de Ángel, el 2 de los Baños de Ariño. Inaugura el Mesolítico pleno de carácter geométrico del Bajo Aragón que, en su momento, se tipificó a partir del conjunto I de la levantina cueva de la Cocina. Las dataciones disponibles (procedentes de Botiquería, Pontet y los Baños) resultan muy coherentes entre sí y llamativamente concentradas en el tiempo, en el tercio central del octavo milenio BP.

Fase C: representa, en el proceso de evolución industrial del Bajo Aragón, la coexistencia en algunos niveles de elementos materiales de aparente distinta filiación cultural: por tanto, esta situación ha de considerarse como propia del Mesolítico final en su transición hacia el Neolítico y se rastrea de forma varia en los diferentes asentamientos. Se conforman ahora los niveles 4 de Botiquería, c inferior de Pontet, IIb de Secans y la parte superior del c 3 de Costalena. Mayoritariamente se produce una progresiva sustitución de los trapecios por los triángulos, manteniéndose todavía el retoque abrupto como el preferente en su conformación y la técnica del microburil para el troceado de las láminas; aparecen en varios asentamientos triángulos de dos lados cóncavos y espina central por lo que se ha relacionado con la fase II de Cocina. Sin embargo, elementos "indicadores" de una fase neolítica se hacen ahora presentes en algunos sitios: cerámicas (unos pocos trozos lisos y otro grande inciso) en Pontet, triángulos de retoque simple bifacial (o en doble bisel) y un perforador en lámina tipo "taladro" en Botiquería. Las fechas disponibles para ubicar esta fase se extienden en un lapso de tiempo de cerca de medio milenio: mientras que las de Costalena y Pontet apuntan hacia el tercio central del séptimo milenio BP (entre 6420 \pm 250 una de Costalena y $6370 \pm 70$ la de Pontet) en Botiquería se remonta al $6830 \pm 50 \mathrm{BP} ; \mathrm{y}$ resaltamos este espacio de los quinientos años C14 que median entre la datación del Mesolítico más tardío (ya con algunas evidencias de industria lítica de atribución neolítica) y la de las cerámicas más viejas controladas en el Bajo Aragón.

Fase D: ofrece la formalización de una industria microlítica compuesta por triángulos y cada vez más segmentos que serán conformados por medio de retoque en doble bisel y con un descenso muy significativo del recurso a la técnica del microburil en su fabricación. La cerámica se extenderá ahora a todos los asentamientos conocidos y con una variabilidad decorativa muy marcada (impresiones cardiales, de gradina dentada y de punzón, incisiones, plásticas de cordones preferentemente lisos además de, en lógica, cerámicas completamente lisas o con incisiones simples en el labio). Su calificación como estadio plenamente neolítico es controvertida pues son pocos y tardíos los argumentos de matiz económico que acompañan a estas evidencias. Los niveles afectados son los 6 y 8 de Botiquería, los c2 y c1 de Costalena, los c superior de 
Pontet, los 3 y 4 de Los Baños (no excavados todavía) y los conjuntos 6 y 11 de Ángel. Las dataciones de los niveles 6 y 8 de Botiquería (en el último tercio del séptimo milenio BP) suceden inmediatamente a las transicionales de Costalena y Pontet. Pensamos que la fecha del nivel c2 de Costalena (en 5480 $\pm 50 \mathrm{BP}$ ) es excesivamente moderna para el conjunto material en él representado que es en todo equiparable a los de Botiquería y Pontet. Considerando exclusivamente el equipamiento de industrias líticas y variedades decorativas cerámicas, el asentamiento de Alonso Norte podría tener cabida en esta misma fase, aunque su datación C14 (del quinto milenio BP) sea decididamente posterior.

Fase E: en Pontet se detecta un nivel -el b- correspondiente al Neolítico avanzado con más abundantes cerámicas pero exclusivamente lisas o con cordones también lisos paralelos al borde de los recipientes: se fecha en 5450 $290 \mathrm{BP}$ y, al estar "sellado" por un nivel estéril -el a- se ha preservado la integridad de la ocupación. No ocurre lo mismo en otros sitios: por ejemplo, en Costalena, cuyos niveles b y a presentan alteraciones postdeposicionales que se manifiestan en una mezcla de materiales neolíticos (todavía geométricos) con otros claramente posteriores (puntas de flecha de reconocida referencia calcolítica). Lo mismo podría suceder en la parte superior de la cueva de la Cocina, tal como se ha apuntado recientemente (Martí y Juan-Cabanilles 2000).

\subsection{La gestión de los recursos}

En lo publicado se alude, aunque sea de forma escueta, a la existencia de una cierta variedad de materias primas utilizadas para la talla de instrumentos: casi siempre variantes de sílex que se distinguen por su color o por la diferente textura de su grano.

Se ha observado en algunos casos (Botiquería, Costalena) un uso diferencial aunque lógico de las distintas variedades de sílex que aparecen en los yacimientos: para utensilios de sustrato que no requieren una técnica demasiado depurada para ser eficaces (raspadores, buriles, raederas...) -en general objetos de utilización doméstica para el procesado y transformación artesanal/industrial-se echaría mano de variedades de menor calidad, mientras que para instrumentos utilizados en trabajos de obtención de recursos primarios -artilugios de caza, acaso pesca y recolección- o de defensa del grupo -armas en sentido amplio- se utilizarán muy a menudo variedades más finas.

Sólo en Secans se ha estudiado la variabilidad de materias primas líticas y su procedencia: se han identificado hasta cinco diferentes que proceden de diversos afloramientos que se encuentran a distancias variables entre los 15 y los 25 kilómetros del asentamiento, en su mayoría en las cuencas altas de los ríos Matarraña y Algás. Por esa razón, las inmediatas orillas de esos ríos, próximo a los abrigos de Botiquería, Secans y Pontet el Matarraña y de Costalena el Algás, serán ricas en nódulos con córtex muy rodados que se encuentran en posición secundaria (Rodanés, Tilo y Ramón 1996: 66-67).

Algunas actividades de aprovisionamiento pueden ser sugeridas mediante el análisis de un muy exiguo lote de restos óseos faunísticos. Frente a los fragmentos de huesos quemados inidentificables en Secans (Rodanés, Tilo y Ramón 1996: 10 y 18) y a los "restos escasísimos que no hacen posible ningún tipo de evaluación sobre su especie (salvo para algunas evidencias de conejo)" en Pontet (Mazo y Montes 1992: 247), los fragmentos de asta y hueso hallados en Botiquería (Barandiarán 1978: 65, 69, 82, 86, 90, 98 y 135) y Costalena (Barandiarán y Cava 1989: 29, 33, 34, 39, 40, 53-55, 66-69, 76 y 119) permiten reconocer algunas de las especies presentes en los tiempos en que se fueron ocupando ambos yacimientos (y a cuyas estratigrafías fueron incorporándose por aportación de sus cazadores y/o consumidores o, en algún caso, por tanatocenosis). A partir de ellos se ha esbozado el cuadro de actividades de caza (Barandiarán y Cava 1989: 159; Rodanés, Tilo y Ramón 1996: 98-99). 
En revisiones de conjunto sobre el tema se ha matizado la entidad de estos lotes de fauna con propuestas que afectan su sentido. Por una parte (Rodanés, Tilo y Ramón 1996.98-99) se ha diferenciado el valor de las muestras de Botiquería (que "ofreció un exiguo conjunto de fauna") y de Costalena ("el conjunto es más amplio... la muestra es cuantiosa"); y también se ha interpretado la exigüidad de restos óseos recogidos (pocos en ambos sitios, escasísimos y nada definitorios los de Pontet y Secans) como que "nunca los hubo o que fueran muy escasos" sugiriéndose que las actividades primarias de caza se habrían desarrollado en otros sitios. También se ha argumentado (Montes 1996.763) que los huesos de conejo de Botiquería, Costalena y Pontet puedan no ser atribuidos a caza y consumo humanos sino a la frecuencia de estos animales en los abrigos durante las etapas de desocupación integrándose, al tiempo, sus huesos en los niveles arqueológicamente fértiles que se ven surcados por madrigueras de conejos ("claramente rastreables, por ejemplo, en el Pontet"). Esta afirmación debe ser matizada, a nuestro parecer, ya que, aunque aquella posibilidad pueda ser contemplada, no ha mediado análisis tafonómico alguno sobre las muestras aludidas y, donde éste sí se ha practicado -en las secuencias de yacimientos levantinos y andaluces como las de Cocina, Nerja, Tossal de la Roca, Cendres y Santa Maira-, se ha constatado el origen antrópico de su presencia y manipulación, resaltándose que el conejo "constituyó una pieza fácil de obtener, que aseguraba las bases mínimas de subsistencia y, por esa razón, era cazado en grandes cantidades" (Pérez Ripoll 1992: 253), si bien es cierto que con mayor intensidad en el Mesolítico que en el Neolítico (Pérez Ripoll 1992: 266).

Pensamos que los pocos restos de fauna del Bajo Aragón mesoneolítico que han llegado hasta hoy deben ser los que han aguantado, mal que bien, la presumible manipulación/rotura inicial por sus consumidores, la acción de fuegos reiterados en las ocupaciones de esos abrigos y, sobre todo, la corrosión por el medio ácido en que han permanecido (Cava 1994: 77). La analítica del sedimento de Botiquería advirtió una elevada proporción de materia orgánica y de fósforo, que sirvió precisamente para establecer un índice de intensidad de ocupación (Alberto y Machín 1985: 60 y 64 y fig.8; y que, con la misma metodología y parecidos resultados, se aplicó en Secans: Cuchi 1996: 34-35); para los edafólogos mientras la materia orgánica tendría su origen en depósitos tanto naturales de vegetación y procesos húmicos como aportados por el hombre, "la acumulación de fósforo sería principalmente de origen humano o animal". En suma, seguimos manteniendo que una cierta (y hasta buena) parte de los carbones (evidentes al excavar los suelos de ocupación de esos yacimientos y que, por ejemplo, en el análisis químico del sedimento de Botiquería significan en forma de partículas muy finas el $40 \%$ de la materia orgánica) y del fósforo (cuyo origen deben ser evacuaciones de hombres y animales que ocuparan el espacio y/o residual de piezas cazadas) así como los abundantes fragmentitos menudos de huesos quemados por todo el espesor fértil de Botiquería y Costalena apoyan nuestra propuesta de una masiva desaparición de la mayoría de los restos óseos que se integraron en aquellos niveles. Reconociendo que la muestra de fauna hoy disponible es menguadísima (tan corta, de hecho, en Botiquería como en Costalena), pensamos que es lo que resta de lo que fueron abandonando los cazadores que en los mismos abrigos llevarían a cabo buena parte de los procesos de preparación (desarticulado, troceado menor, cocción) y desde luego los de consumo de las piezas capturadas.

Eliminados fragmentos óseos inidentificables menores, quedan en Botiquería 175 restos de fauna determinable; a un lado las especies que pudieran estar aquí como efecto de tanatocenosis naturales en el abrigo (aves con 2 restos en el nivel 4; y lince con 3 restos en el nivel 6 ¿murieron naturalmente aquí o fueron cazados por los prehistóricos?) quedan los huesos que más seguramente aportaron la caza y consumo por parte de los prehistóricos: el conejo, con 124 restos presentes en todos los niveles, y, entre los mamíferos mayores, el ciervo (en total 34 fragmentos) que aparece así mismo en toda la secuencia, los propios de alguna/s etapa/s que son el caballo en lo más viejo (nivel 2: 4 restos) y el jabalí luego (niveles 4, 6 y 8: 6 restos en total) y la presencia excepcional del sarrio (nivel 4: 1 resto) y del corzo (nivel 8: 1 resto). Del mismo modo, la alta cifra de residuos óseos (cerca de cuatro millares) recogidos en Costalena se reduce drásticamente a poco más de un centenar de identificables entre los que una vez que se apartan las especies que pueden 
hallarse en el depósito del yacimiento por procesos naturales (caso de algunos roedores -entre ellos, algún resto de rata de agua-, de microvertebrados no definidos y de un puntual lince) quedan 57 restos referibles a actividades de caza por el hombre: significan una presencia constante y mayoritaria del ciervo (34 restos presentes en toda la estratigrafía excavada) y esporádica del caballo (1 resto en el nivel c3) y de la cabra ( 5 restos en c2/c1 y 1 en b+a). Aquí, el conejo sólo está representado por 17 restos ( 6 en c3, 1 en c3/c2, 5 en c 2,1 en c $2 / \mathrm{c} 1$ y 3 en el c indiferenciado).

Llama la atención la cierta variedad (pese a lo reducido de la muestra conservada) de especies representadas en la fauna cazada. En los abrigos del Bajo Aragón están presentes el ciervo y el caballo en Costalena y el ciervo, el jabalí, el caballo y el sarrio (los dos últimos con presencia esporádica) en Botiquería; en ambos yacimientos el espectro faunístico se amplía algo en el Neolítico con la aparición de restos de cabra en Costalena y de corzo en Botiquería, pero la escasez de sus restos sólo permite marcar diferencias sutiles de estrategias de caza en el paso del Mesolítico al Neolítico como, por ejemplo, la presencia del caballo en los niveles mesolíticos de base. Evaluando el significado paleoclimático de esa muestra de fauna, salvo el conejo que se da en la actualidad en paisajes con vegetación arbustiva escasa y cuya presencia es constante en los yacimientos aludidos, varias de las especies mayores cuyos restos hemos recuperado prefieren terrenos más arbolados que los existentes en la zona en la actualidad: dato que concuerda plenamente con la reconstrucción paisajística elaborada a partir de los análisis polínicos. La presencia de restos de cabra y, en menor medida, de sarrio implica el acceso de los cazadores a un entorno diferente -por altitud y topografía- al inmediato de ambos yacimientos, sugiriendo una mayor movilidad del grupo en su actividad cinegética.

Contadas vértebras de pez de especies no identificadas de tamaño medio (una en el nivel 3 de Botiquería; y en Costalena dos en el nivel c2, una en la transición del c2 al c1 y una en el c genérico) apoyan la suposición de prácticas de pesca en los próximos cauces del Matarraña y Algás.

Las referencias al medio vegetal se basan en los análisis palinológicos de Botiquería, Secans y Pontet (López, López y Sánchez 1991; López 1992; López y López 1996); faltan absolutamente análisis de macrorrestos que es difícil que se hubieran conservado a causa de la aludida acidez del suelo salvo en el caso de algunos fragmentos reconocibles de carbón. Por ello sólo muy parcialmente se podrán plantear las cuestiones que interesan al arqueólogo: bastante bien la de reconstrucción del paisaje vegetal en el lapso temporal en el que los abrigos fueron ocupados; prácticamente nula la del aprovechamiento de los recursos vegetales disponibles por parte del hombre para diversas finalidades (combustible, alimento, usos industriales); y de modo ambiguo las referencias a las alteraciones antrópicas en la composición del paisaje natural, incluyendo ahí la posibilidad de la introducción de actividades agrícolas en el transcurso del Neolítico.

Diseñan el paisaje vegetal de aquel tiempo en el tercio final del Matarraña lo genérico de un paraje templado de ámbito mediterráneo (con una cubierta arbórea más densa que la actual, en bosquetes mixtos o de parque según parajes) y lo particular de especies puntuales propias de proximidad a cauces de río. El paisaje del entorno de Botiquería se define (López, López y Sánchez 1991: 400) como bastante arbolado "con formaciones mixtas de coníferas y frondosas" habiendo en toda su secuencia altos porcentajes de pino carrasco (Pinus halepensis: hasta casi un $50 \%$ ), apreciables de Quercus y Corylus (próximos al 10\%) y minoritario de otras concretas como Fraxinus y acaso Olea y, en tiempos de vegetación más abierta, de otras arbóreas del género Juniperus. Los cuadros representados en las muestras palinológicas de los dos yacimientos vecinos resultan prácticamente similares (López 1992: 237): en Secans domina el pino sobre un cortejo de sauces, álamos, alisos y avellanos y en Pontet son también máxima la proporción del pino y complementarias las de Quercus, avellanos y sauces. 
De los análisis palinológicos se ha deducido algún tipo de intervención humana sobre el medio vegetal: — en el paisaje de Botiquería "la acción antrópica es patente a lo largo de todo el diagrama" (López, López y Sánchez 1991: 395)" según el testimonio deducido de "las antrópicas (Rumex, Plantago, Crucíferas, Rubiáceas, etc.)" (López 1992: 235), significándose en la parte alta del diagrama (niveles 6 a 8) "un nuevo efecto antropizador, degradativo del bosque, con la consiguiente proliferación de especies nitrófilas" (López, López y Sánchez 1991: 401-402); la presencia y significado puntuales en los niveles 5 y 6 de Vitis se ofrecen con recelos ("puede deberse a una contaminación o bien a su estado como especie silvestre": López, López y Sánchez 1991: 401).

— en el cuadro paleobotánico del Pontet (López 1992: 237) “entre las herbáceas destacan las Asteráceas ligulifloras, acompañadas por un cortejo de plantas antrópicas que indican la actividad del hombre desde el inicio del Neolítico, presencia que queda de manifiesto en algunos pólenes de cereal $(1,08 \%)$ y de las ruderales que acompañan a éstos;... destacan los valores altos de Ephedra en las muestras superiores, coincidiendo con los valores de Cistáceas (Helianthemum), indicando procesos de degradación del suelo"; y se ha concretado (Mazo y Montes 1992: 246) que ahí aparece el cereal "en el nivel b (Neolítico reciente), dentro de un medio vegetal más variado y húmedo de como se presenta actualmente";

— en Secans se encontraron "Poáceas (gramíneas) y Fabáceas (leguminosas) que mantienen valores constantes a lo largo de toda la secuencia, y las denominadas plantas antrópicas (Plantago, Rumex) así como de las Malváceas, Convolvuláceas o la Artemisia... la presencia de dos pólenes de cereal (pólenes superiores a 45 micras) nos lleva a pensar en una incipiente agricultura. Aunque su porcentaje no es alto $(1,1 \%)$ es suficientemente indicativo de su presencia en un área próxima al hábitat" (López 1992: 237); más en concreto (López y López 1996: 88) la presencia del cereal se ubica en la cota de los $25 \mathrm{~cm}$ de profundidad y la de las Fabáceas en su máxima entre las de 50 y 25.

Los análisis palinológicos coinciden en advertir la acción antrópica en el paisaje circundante de los asentamientos. En el caso de Botiquería, la degradación progresiva del bosque, que se intensifica en la parte superior de su estratigrafía, ha de deberse, en lógica, a la presión humana a través de la tala de la madera para su aprovechamiento como combustible para los hogares. En cuanto a la detección de prácticas agrícolas, los indicadores directos de su inicio son ciertamente algo recientes: los pólenes de cereal en Pontet se presentan en el nivel b (Neolítico reciente) y en Secans (cuyo muestreo se articula en un conjunto inferior -'zona polínica I'-y otro superior -'zona polínica II ( $30-15 \mathrm{~cm})$ - ) están en la parte alta de la estratigrafía correspondiente al nivel I ("a los $25 \mathrm{~cm}$ se detecta muy puntualmente polen de cereal, que indicaría un aporte alógeno a la zona de estudio” según López y López 1996: 88).

Botiquería, Costalena y Pontet han entregado instrumentos cuya morfología y huellas se suelen atribuir a actuaciones sobre la vegetación.

- Del nivel 4 de Botiquería procede un bloque de arenisca de forma subparalelepipédica (140 mm de largo, 85 de ancho y 45 de espesor) con una de sus caras mayores alisadas por uso, considerado "elemento durmiente sobre el que pasase... algún cuerpo sólido para redondearlo, alisarlo o desmenuzarlo" (Barandiarán 1978: 113).

- En Costalena se describen como piezas referibles, por su tipología, a manipulaciones sobre soportes vegetales: del nivel c1 "1 fragmento de piedra de molino"... "(¿destinada a la moltura de grano?)" (Barandiarán y Cava 1989: 65 y 108) y "1 percutor sobre canto rodado" (ibid.: 66); del nivel b "un trozo de probable hacha pulimentada de sección oval"... "empleada en el trabajo de la madera" (ibid.: 69 y 108); y de la transición del b al a, un canto de arenisca "desgastado parcialmente por frotamiento" (ibid.: 69 y 108). En nuestra visita al Museo de Zaragoza de 1998 revisamos las dos piezas halladas en el nivel c1. El fragmento de piedra de molino (sigla: Co.5P.229.85) es parte del soporte/bloque 
durmiente en arenisca de grano medio y conserva la depresión central producida por su uso en el molturado de materias vegetales de cierta dureza. El "percutor" (sigla: Co .2Ñ.174.150) es un canto rodado de sección gruesa con estigmas de uso (unas como saltados/muescas algo profundos relativamente contiguos concentrados en la extensión mayor de ambas caras y en uno de los extremos; otras producidas por frotamiento reiterado que ha llegado a rebajar bastante uno de sus flancos/aristas distales) que responden respectivamente a usos en el golpeo (percusión) y la abrasión, según piezas similares que están siendo reconocidas en bastantes lugares mesolíticos y neolíticos y que se habrían destinado a usos no bien determinados: como la muy variada muestra del sitio navarro de Aizpea "de función difícil de determinar...abrasión, percusión, piqueteado o raspado" (Cava 1997: 154-155 y figs. 9.2/3).

— En el Pontet "la aparición de molinos y volanderas se produce ya desde el nivel c inferior" (Mazo y Montes 1992: 247), concretándose (Montes 1996: 764) "dos piedras durmientes, dos volanderas $\mathrm{y}$ dos trozos de hacha" en el nivel c superior y un fragmento de molino en el nivel b.

Se trata, por tanto, de un efectivo de piezas arqueológicas que normalmente se relacionan con actuaciones sobre un medio o soporte vegetales: cascado o desmenuzado de simientes o frutos (bloque de arenisca de Botiquería niv. 4 y "percutor" de Costalena c1), molienda (piezas de "molino" de Costalena c1, Pontet c sup. y Pontet b), otras manipulaciones por frotamiento (pieza de Costalena b/a) y corte de madera ("hachas" de Costalena b y Pontet c sup.).

El aprovechamiento de los recursos vegetales es hecho comprobado en sociedades de la primera mitad del Holoceno: las condiciones climáticas más favorables permiten un desarrollo de la cubierta vegetal y, en ella, de múltiples recursos explotables por el hombre. En muchos yacimientos contemporáneos a éstos del Bajo Aragón la aplicación de sistemas de recuperación de macrorrestos vegetales y su identificación carpológica revelan un consumo intenso de esos recursos predecibles, fáciles de recolectar y nutritivos y explican la presencia de un lote instrumental preciso para su recolección y transformación: una parte tiene caracteres tecnotipológicos muy definidos y precisos (hachas pulimentadas, por ejemplo), el resto (cantos o bloques durmientes con huellas de percusión o frotamiento) pueden haber sido utilizados para diversas manipulaciones de productos tanto silvestres como ya cultivados. Las recientes investigaciones en asentamientos de la alta cuenca del Ebro o del Cantábrico van en esa dirección: así, en el abrigo de Aizpea, en el Pirineo navarro, aún reconociendo la marcada diferencia en las condiciones paisajísticas y ambientales con respecto a las del Bajo Aragón, se ha recogido -en un grueso depósito mesolítico coronado por una sedimentación bastante más débil correspondiente a época neolítica- una buena muestra de vegetales aptos para la alimentación humana compuesta por avellanas y diversos pomos (acerolos, servales de cazadores, mostajos y manzanas silvestres), advirtiéndose que pudieron haberse utilizado otros que se conservan muy mal en los sedimentos arqueológicos como bellotas, cerezas, endrinas y cortezas de algunos árboles, amén de verduras o brotes tiernos que son imposibles de detectar (Zapata 2001). Avalando esa hipótesis, el análisis químico de elementos traza del esqueleto de una mujer inhumada al final del Mesolítico en ese mismo yacimiento muestra en ella una alimentación básica de elementos vegetales (carbohidratos) y bastante deficitaria en proteínas de origen animal (de la Rúa y otros 2001).

\subsection{Los sistemas de ocupación}

En varias ocasiones se han definido las características de los sistemas de ocupación (situación y acondicionamiento de cada sitio, articulación de las ocupaciones en grupos y con respecto a los paisajes circundantes) tanto del propio Bajo Aragón como de otros territorios de interior de la cuenca del Ebro, 
por separado (Alday 1995; Rodanés y Ramón 1995) o en su conjunto (Cava 1994). Concretando lo que aquí se conoce por ahora aludiremos a los aspectos más significativos.

Se define en el tiempo en que los abrigos fueron ocupados un paisaje de bosque mixto abierto (más arbolado que hoy) de tipo mediterráneo: entre las especies arbóreas representadas hay un dominio general de pinos carrascos, cierta cantidad de Quercus y las lógicas matizaciones puntuales (dependiendo de parajes concretos: en suelos, proximidad a cauces fluviales, solanas/umbrías,...) de avellanos, fresnos, sauces, álamos, alisos, enebros, ...

Los asentamientos se sitúan en valles de ríos secundarios, afluentes o subafluentes del Ebro y muy cerca del propio cauce, tanto en altura como en distancia lineal. Es decir, que son lugares muy cómodos para el acceso directo e inmediato a la corriente y a los recursos que ésta pueda proveer: Costalena a unos 100 metros de distancia del río Algás y a unos 15 metros por encima de su cauce, situación que se repite casi idéntica en Botiquería y Secans con respecto al río Matarraña y, algo más alejado, en Pontet con respecto al cauce de este mismo río.

Las formaciones areniscas de cierta potencia habituales en la geología del territorio han generado, por erosión diferencial de las capas más blandas subyacentes, amplias viseras que, como abrigos rocosos, proporcionaron a los mesolíticos un mínimo resguardo de las lluvias y vientos dominantes (pues se orientan preferentemente los abrigos al sur y este). Estos abrigos son de poco fondo y diversa amplitud y se protegen con viseras salientes: bastante grandes como Llop ("la cueva del..."), Botiquería (22 metros de frente por 2,5 de voladizo actual) o Costalena (12 metros de frente y 3,5 de voladizo actual), más pequeños como Pontet y Secans; los sitios emplazados en zonas descubiertas ("de aire libre") realmente se hallan al resguardo de próximos cantiles rocosos como Serdá, Sol de la Piñera o Alonso Norte. Las zonas ocupadas en los suelos de esos abrigos no se restringen a las superficies directamente protegidas por las viseras o salientes (que en algunos casos pueden ser pequeños) sino que se extienden por un área mucho mayor: calculamos, por ejemplo, una amplitud original del yacimiento de Costalena de 150 a 170 metros cuadrados.

La disgregación de la roca arenisca junto a aportes de origen antrópico (especialmente una notable masa de cenizas y pequeños carbones) ha dado lugar a una sedimentación fina que forma paquetes estratigráficos en los que no es difícil individualizar diferentes unidades estratigráficas a partir de la coloración del sedimento: de tono gris o negruzco correspondiente a formaciones de hogares y claro y amarillento cuando se frecuentan poco, o nada, esos suelos (en las excavaciones prácticamente inéditas de J. Tomás en Botiquería se alude -sin más justificación analítica-al uso de carbones de pino en los hogares asentados en el yacimiento: Tomás y Vallespí 1960: 206). Son de fácil reconocimiento algunos acondicionamientos del espacio (hogares fundamentalmente): los cantos o bloques de piedra que aparecen en el yacimiento son alóctonos (sobre todo, cantos rodados de los cauces próximos) y aportados por los prehistóricos.

Las estructuras de acondicionamiento hasta ahora recuperadas son bastante simples y acaso reflejan una ocupación no permanente de los abrigos: hogares sencillos (de cubeta y delimitados por círculos de piedras o en forma de lentejones con amontonamiento de piedras o, incluso, simples manchones de cenizas) en todos los sitios excavados a fondo -veánse como ejemplos llamativos los de Botiquería (Barandiarán 1978: lám. VIII) o Costalena (Barandiarán y Cava 1989: lám. 6)-y además, puntualmente, agujeros practicados para calzar postes en Pontet (Mazo y Montes 1992: 246) y alguna cubeta y una dispersión horizontal de grandes piedras en Secans que pudieran ser "los restos de un muro que cerraría una cabaña de planta oval de unos 3,5 m de diámetro máximo" (Rodanés, Tilo y Ramón 1996: 30).

La posición de estos sitios facilita el acceso a una variedad territorial de paisajes y recursos que habrán sido aprovechados de modo integral proporcionando a sus ocupantes una variada dieta. Acaso sólo el aprovisionamiento de carne de cápridos -excepcional tanto en Botiquería (sarrio) como en Costalena (cabra)-implique un esfuerzo mayor en el desplazamiento para las batidas de caza a zonas de media a "alta" montaña: especialmente si se trata de la cabra montés, pues el hábitat del sarrio es menos elevado-de media montaña-ocupando 
a menudo, y especialmente durante la invernada, los bosques del piso inferior siempre que la presencia del hombre no se lo impida.

En las zonas más intensamente prospectadas -los cursos medios de los ríos Matarraña y Algás, por ejemplo-se reconocen altas concentraciones de sitios ocupados: aquí se dan dentro de un área cuya distancia máxima entre extremos no supera los $15 \mathrm{~km}$ las secuencias largas de Botiquería, Pontet y Costalena y ocupaciones puntuales de Secans, Serdá, Sol de la Piñera, además de sitios localizados pero no excavados como el abrigo Ahumado y otras citas menos concretas. El equipamiento y las secuencias paralelizables impulsan al reconocimiento de una densidad de población notable que se sirve de un equipamiento parecido y desarrolla comportamientos similares que permiten definir un "modelo" propio.

La potencia de algunas estratigrafías y la secuencia de las dataciones absolutas obtenidas sugieren que los sitios fueron visitados reiteradamente a lo largo del tiempo. Existía pues una tradición arraigada en la explotación de determinados territorios y, lógicamente, de ocupación de unos refugios idóneos por sus condiciones de habitabilidad o por su situación estratégica sobre los parajes circundantes. La comprensión de esos comportamientos, por lo visto a partir de las muestras recuperadas y la metodología de identificación/explicación que llegamos a (o hemos sabido) desplegar, habría de responder a varios interrogantes: ¿estamos ante una población fija o sólo estacional?, ¿habitan siempre en el mismo abrigo o área geográfica restringida u ocupan rotativamente varios abrigos más o menos próximos?, ¿dónde se encuentran estos otros asentamientos?

Entre otras, se han planteado (Rodanés y Ramón 1995: 114) tres posibilidades de explicación de los yacimientos en relación con la explotación económica del medio para evitar un rápido agotamiento de los recursos: la primera consistiría en considerar a toda la zona como lugar de asentamiento estacional dependiente de otro foco externo; la segunda contemplaría la adopción de un sistema rotatorio durante periodos cortos de modo que se alternara la ocupación de los distintos abrigos a medida que se agotaban los recursos de sus áreas de explotación inmediata; la tercera, por fin, aceptaría la posibilidad de continuidad ocupacional en cada uno de los asentamientos suponiendo una mayor celeridad en el agotamiento de los recursos que debería superarse con la introducción de sistemas económicos de producción de alimentos, hecho que se observa (según ellos, a nosotros los datos no nos parecen determinantes) -aunque sea de forma leve- a partir del Neolítico.

Nuestra opinión al respecto matiza varios de esos conceptos, asegurando, al menos: a) que cada unidad de depósito (las que haya en el interior de cada nivel o estrato) se corresponde con un asentamiento temporal (coincidente con estaciones del año o no) en ese lugar; b) que se ha de reconocer, por tanto, que cada una de esas unidades de depósito debe articularse con (mejor que "depender de") otras dentro o fuera del propio Bajo Aragón; y c) que, con los registros arqueológicos actuales, no somos capaces de definir cuál es el grado de interrelación entre los diferentes asentamientos del propio Bajo Aragón.

\subsection{Mesolítico y Neolítico del Bajo Aragón en su contexto de la cuenca del Ebro}

La diferencia en el enfoque de la investigación en las diversas regiones de este extenso territorio, derivada sin duda de la parcelación de los espacios en relación con proyectos concretos de investigación, que se constataba hace algún tiempo, se está reduciendo en los últimos años.

Las perspectivas de conocimiento a medio plazo son altamente esperanzadoras para la cuenca del Ebro, una de las zonas peninsulares donde se podrán definir bien las formas de vida de los últimos cazadores/recolectores y su proceso de cambio hacia situaciones neolitizadas. Aunque la provisionalidad de los datos ahora mismo disponibles (hay un buen número de yacimientos excavados hace poco tiempo o en proceso de excavación y aún no publicados en profundidad) sigue dificultando todo trabajo de síntesis y exige de cualquier intento 
de teorización sobre modelos de comportamiento de los prehistóricos la flexibilidad necesaria para ir acomodándose a los datos que constantemente se renuevan y amplían.

Cuando sistemáticamente se prospectan zonas determinadas se obtienen identificaciones de sitios que van colmando muchos de los "vacíos" de los mapas de distribución de yacimientos. En la provisionalidad del conocimiento -que ahora mismo se está desarrollando-no estamos de acuerdo con la interpretación de tales vacíos (Martí y Juan Cabanilles 2000) como indicadores de que en el Epipaleolítico se haya de reconocer "una baja demografía para la Península", por "estar muy desigualmente repartida" e, incluso, por "una discontinuidad en el poblamiento, una separación entre los grupos de los distintos territorios". La experiencia acumulada por los equipos de investigación de la cuenca del Ebro muestra lo ficticio y provisional de tales vacíos y lo relativo de la supuesta baja demografía: respecto a lo primero, hay ya asentamientos mesolíticos en el Alto Aragón (Forcas II o Peña 14 de Biel) que empalman prácticamente con los reconocidos de antes en la Navarra pre- y pirenaica (Padre Areso, Zatoya o Aizpea); respecto a lo segundo, la intensificación en las prospecciones muestra redes bastante densas de localizaciones que permiten asegurar un alto grado de ocupación del territorio: p.e., en Álava y la inmediata Navarra media occidental donde se conocen hoy en un área de menos de $100 \mathrm{~km}^{2}$ ya seis asentamientos con niveles meso/neolíticos (Alday 2000: 106).

A modo de ensayo -y a partir de las limitaciones y provisionalidad de los datos, que hemos recordadointentamos de nuevo describir los sucesos y cambios culturales que se aprecian en la cuenca del Ebro a lo largo de tres milenios (aprox. de comienzos del noveno a comienzos del sexto en cronología C14 BP) siguiendo el modelo de interpretación utilizado reiteradamente por quienes han abordado el tema de forma más general (Utrilla, Cava et alii 1997; Utrilla 2000) o en particular hacia una fase cultural (Cava 1994) o a un área más restringida (Alday 1995 y 2000).

La diversidad regional en un espacio tan extenso se manifiesta en bastantes ocasiones y puede explicarse en razón de la proximidad de las diferentes agrupaciones de yacimientos controlados (en el Bajo Aragón, en el Alto Aragón, en el Pirineo navarro, en Navarra media-Álava) con respecto a las áreas externas que han podido influir en cierto modo sobre esas agrupaciones territoriales, suscitando relaciones o, incluso, generando las mismas ocupaciones. Esta diversificación se produce de forma parcial, afectando a los ritmos de la evolución en cuanto a su cronología y, en especial durante las fases recientes del proceso (final del Mesolítico e inicios del Neolítico), a la variabilidad tipológica del equipamiento material.

La base de partida es muy similar en toda la cuenca del Ebro, produciéndose una ocupación habitual, similar a la descrita para el Bajo Aragón -en abrigos ubicados en valles secundarios con amplias posibilidades de explotación diversificada-, que se traduce en la formación de niveles de denticulados (o macrolíticos) en un lapso temporal que se extiende durante casi un milenio (según las fechas extremas de Forcas Ib en $8650 \pm 70$ y de Kanpanoste Goikoa III inferior en $7620 \pm 80$ ) y ofrece una cierta mayor antigüedad en el Alto Aragón y en el Bajo Aragón que en el oeste de la cuenca. A los niveles conocidos de esta fase cultural en el Bajo Aragón, habrá que añadir los Ib de Forcas II y b de Peña 14 (Biel) en el prepirineo aragonés y los IV de Mendandia, III inferior de Kanpanoste Goikoa y V de Atxoste en Treviño y Montaña Alavesa. Es problemática su articulación con estadios culturales o industriales anteriores, pues son todavía pocos y dispersos los niveles que enlazarían el Paleolítico terminal con esta situación. Todo hace suponer que es ésta-la fase de denticulados o macrolítica- la primera ocupación relativamente densa del espacio interior de la cuenca del Ebro y que sigue unos parámetros -en cuanto a elección y estructuración de los asentamientos y de los territorios de explotación-que después continuarán vigentes puesto que, en la mayoría de los sitios, supondrán los niveles con este equipamiento la base de una secuencia estratigráfica continuada.

Los niveles anteriores en el tiempo presentan una industria caracterizada, desde el punto de vista tipológico, por las puntas y laminitas de dorso. En las cuevas de Abauntz y de Zatoya considerábamos sus respectivos niveles $\mathrm{d}$ y Ib (fechados a mediados del décimo milenio el primero y en el último tercio del noveno el segundo) como la liquidación del previo Paleolítico terminal y sin continuidad inmediata (se reconocen evidentes 
hiatus en las secuencias respectivas de ambas cuevas) con los niveles posteriores, de datación ya neolítica. La misma situación se repite en el centro de la cadena pirenaica en los niveles 9 y 7 de Forcas I (en discontinuidad estratigráfica con respecto al paquete sedimentario de Forcas II) y en Parco (datados en $9715 \pm 75$ y $9360 \pm 140$ los dos del primer sitio y en $9290 \pm 670$ el segundo). En la base de algunos abrigos que después desarrollarán una secuencia prolongada de ocupaciones meso-neolíticas -como Mendandia, Montico de Charratu y Fuente Hoz en el oeste de la cuenca, Peña 14 en el Alto Aragón y Ángel en el Bajo Aragón- se detectan también niveles de dorsos sin ocupación previa; de todos ellos, por ahora sólo conocemos la datación del de Mendandia en $8500 \pm 60$ y se nos hace todavía difícil calibrar el grado de continuidad/discontinuidad entre esas situaciones con dorsos y las suprayacentes de denticulados.

En Cataluña se detectan desde casi los inicios del Holoceno asentamientos con una diversa caracterización industrial: unos, de aspecto sauveterroide, con una base microlítica de abundantes segmentos y triángulos pigmeos obtenidos por medio de la técnica del microburil: Filador, Balma Margineda o abrigo del Gai, cuyo inicio se puede situar algo antes del inicio del décimo milenio con perduración hasta mediados del noveno BP (García Argüelles, Nadal y Fullola 1999: 82). Y otros, un poco más tardíos pero parcialmente contemporáneos de los anteriores en su fase final, con industrias masivas sobre cantos de materias primas de peor calidad (autóctonas e inmediatas al sitio): Font del Ros, Roc del Migdia o Sota Palou, cuya cronología se determina a lo largo de todo el noveno milenio BP y que presentan ciertas concomitancias con los niveles de denticulados o macrolíticos de la cuenca del Ebro. Derivando estos conjuntos de utensilios masivos también por el sur de Francia, constituyen una facies industrial que, según recientes interpretaciones, sería el reflejo de una variabilidad "estratégica y situacional" basada en una compleja interacción de diferentes factores como las actividades llevadas a cabo en el sitio, la duración e intensidad de la ocupación, las restricciones impuestas por la materia prima disponible, la estacionalidad-verano/otoño- en el aprovisionamiento de alimentos, etc... (Pallarés y Mora 1999: 66-67). Apoyando esta tesis no rupturista entre ambos lotes industriales -o facies-los niveles IIb y IIa del sector exterior de la alicantina cueva de Tossal de la Roca presentan situaciones intermedias entre esas dos variantes industriales ya que, sobre una base de denticulados y de "algunas piezas macrolíticas de caliza", hacen su aparición los elementos geométricos (segmentos, triángulos y piezas de dorso curvo) con dataciones de entre fines del décimo y fines del noveno milenios BP $(9150 \pm 100$ y 8530 \pm 90 en IIb, y de 8350 y $8050 \pm 120$ en IIa) (Cacho et alii 1995: 85-87 y 93).

La irrupción masiva de los geométricos -de base trapecial en un primer momento- es también un fenómeno generalizado y homogéneo en toda la cuenca del Ebro. Pero, curiosamente, el ritmo cronológico de su introducción se invierte respecto a la de la fase anterior: así, y tal como se ha señalado repetidamente (Cava 1994: 73, Utrilla, Cava et alii 1998: 176-177 o Utrilla 2000), algunos abrigos del oeste de la cuenca presentan dataciones que remontan al primer tercio del octavo milenio, como la base de Aizpea I, el nivel d de la Peña o el III de Fuente Hoz (éste con pocas referencias bibliográficas). Entretanto, en el este el arranque de esa facies se sitúa en el tercio central de ese milenio (niveles 2 de Botiquería y 2 de los Baños en el Bajo Aragón y a de Peña 14 de Biel en el Prepirineo), prolongándose esa situación en su último tercio (niveles II de Forcas y e de Pontet). Esta secuencia cronológica del sector oriental de la cuenca del Ebro debe ponerse en relación con los todavía pocos niveles de esas características datados en el sector central del ámbito mediterráneo peninsular: por ejemplo, el I del sector exterior de Tossal de la Roca (en 7660 y 7560 800 )

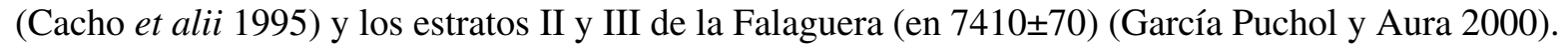

La superposición de cronologías entre los dos estadios reseñados (las más recientes del de denticulados y las más antiguas del de trapecios abruptos) y la presencia de bastantes piezas denticuladas en niveles con ya intensa geometrización (así en la fase Aizpea I y en los niveles 2 de Botiquería, III inferior de Mendandia, o I de Tossal de la Roca, por ejemplo) son hechos que se van reconociendo: permiten, por un lado, establecer interacciones entre ambas facies y, por otro, basar esa diversidad tecnotipológica más en necesidades funcionales que en dualidades culturales. 
La última fase del Mesolítico-la que podemos considerar como transicional por significarse siempre como la previa a la aparición de los primeros síntomas de neolitización-presenta diferentes soluciones industriales detectables, como es habitual, en lo lítico. Atribuiríamos esta decantación diferencial a la variabilidad en la procedencia de los estímulos neolitizadores que incidirán sobre la uniforme base geométrica anterior aunque todavía ahora sean apenas palpables. Determinamos la diferenciación entre:

a) un grupo de adscripción mediterránea cuya característica más aparente, por generalizada, es la presencia de triángulos de espina central (tipo Cocina) que se extiende por Levante y por el sector oriental de la cuenca del Ebro. La presencia de una plaqueta con decoración geométrica en el nivel IV de Forcas, muy similar a las de la fase II de Cocina, evidencia una común concepción artística o simbólica, además de artefactual, en un amplio territorio. Remontándose a una cronología muy antigua en el Alto

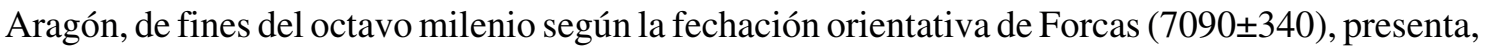
como ya se indicó en su lugar, una larga perduración en el tiempo en el Bajo Aragón (desde la data de $6830 \pm 50$ de Botiquería 4 hasta la de $6310 \pm 170$ de la parte superior de Costalena c3), introduciéndose ya aquí varios elementos que serán característicos de posteriores situaciones neolitizadas como los geométricos de doble bisel en Botiquería o las cerámicas más antiguas de Pontet. Mientras que en Forcas esta etapa tiene una cronología muy próxima a la de sus niveles con cerámica, en el Bajo Aragón (con fecha un poco más reciente que va muy bien con la presencia de algunos elementos "neolíticos" en su industria lítica) la distancia temporal que media entre ambas situaciones se dilata considerablemente: ¿podríamos pensar en algún tipo de abandono o intermitencia en la ocupación de los sitios?; de momento, la disposición de una sola fecha nos obliga a ser cautos en la emisión de hipótesis, y

b) un grupo de más clara referencia continental que afectaría a los asentamientos localizados en situación más próxima al cordal pirenaico. Las armaduras, frecuentemente de perfil triangular, con retoque inverso o simple para adecuar la base y algunas puntas de dorso triangulares son los referentes tipológicos en lo lítico, constituyendo la fase II de Aizpea el ejemplo más válido de este modelo (Cava 1997: 158) que se extiende por un territorio bastante amplio afectando a grupos establecidos desde el Pirineo central (Balma Margineda) hasta el Cantábrico (Kobeaga II o Pareko Landa en la costa vizcaína) (Aguirre, López Quintana y Sáenz de Buruaga 2000).

En este complejo, el núcleo de Álava y de la inmediata Navarra media, por su situación geográfica estratégica en las comunicaciones entre el continente y la Península Ibérica y entre ambientes de influencia mediterránea y el Cantábrico, podría representar un territorio intermedio entre ambas situaciones que sólo podrá ser definido cuando culminen los estudios pormenorizados de yacimientos de tanta entidad como Fuente Hoz, Mendandia o Atxoste.

La neolitización afecta de forma desigual -en intensidad y cronología-a este amplio territorio. También se detectan ahora las dos áreas de influencia diferenciadora: la oriental donde lo cardial se impone con mayor o menor fuerza según condicionantes particulares de norte a sur; y la occidental donde esa variante decorativa aparecerá sólo de forma puntual (Peña Larga, Atxoste..) y es, en general, tardía, mientras que las cerámicas más antiguas (aunque por margen no excesivo) presentan otros tipos decorativos más sencillos (impresos, incisos, plásticos) o son preferentemente lisas.

La primera de las áreas del Neolítico en la cuenca del Ebro, representada por los núcleos del Alto y del Bajo Aragón, presenta una problemática diversa. Como se ha relatado ya, los abrigos del Bajo Aragón muestran una gran variedad de decoraciones (incluyendo sistemáticamente la cardial) en una fase cronológica bastante reciente-del último tercio del séptimo milenio- próxima en el tiempo al de lo epicardial costero. En ese tiempo las actividades productoras son difíciles de detectar (imposible en los escasos huesos animales) y tardías (las que determinarían directamente intervenciones agrícolas asentadas). Por tanto, parece que 
la función de los abrigos se mantiene en los mismos parámetros de aprovechamiento de recursos tanto para estas comunidades como para las anteriores, desarrollándose por unas y otras similares actividades básicas de caza y, posiblemente y en lógica, de pesca y recolección de vegetales.

En contra, en el Alto Aragón la situación es bien diferente, evidenciándose una adopción temprana de los modos de vida neolíticos: primero sólo de la cerámica, desde los mismos inicios del séptimo milenio tal como se deriva de los niveles V y VI de Forcas y, poco después, de todo el cortejo de registros que evidencian el arraigo de las actividades económicas productivas según se advierte ya en el nivel VIII de Forcas y desde las fases más antiguas de la ocupación de las cuevas de Chaves (del nivel Ib) y del Moro de Olvena, datadas en el segundo cuarto del mismo milenio. La antigüedad de este comportamiento nos anima a aceptar la opción repetidamente planteada por P. Utrilla en cuanto al origen inmediato de los estímulos que inciden en la neolitización del área, según la cual procederían de territorios transpirenaicos provenzales utilizando, las comunidades que ocupan ambos territorios, las vías naturales que atraviesan el Pirineo oriental por cotas poco elevadas siguiendo el pasillo que diseñan los cursos de los ríos Têt y Segre; la Balma Margineda, a orillas del río Valira, afluente del Segre, presenta en su nivel III unas dataciones muy similares para la constatación de una práctica agrícola y ganadera ya reseñable en el registro arqueológico. La ausencia, por el momento, de dataciones tan antiguas en el litoral de Cataluña y la más complicada comunicación este-oeste entre los inmediatos valles del prepirineo son argumentos que reforzarían tal hipótesis.

En el occidente de la cuenca del Ebro la neolitización comienza a manifestarse de forma palpable en el registro arqueológico, salvo alguna excepción que se reseñará, en el último tercio del séptimo milenio, con pocos desfases cronológicos entre unos espacios y otros pero con una variable acogida de las formas económicas productivas, siguiendo el modelo previo de duplicidad de influencias en el territorio: de lo continental, por un lado, y de lo mediterráneo, por otro.

$\mathrm{Si}$, por una parte, una tónica continuista generalizada se traduce en la ocupación de los mismos territorios y abrigos que en las fases previas, incluso sin solución de continuidad estratigráfica, por otra-y casi a la vezen tierras riojanas, en las estribaciones montañosas de ambas márgenes del Ebro (los abrigos de Los Husos y de Peña Larga en la Sierra de Cantabria y Cueva Lóbrega en la de Cameros), se va afianzando un hábitat neolítico que inaugurará la ocupación de las cavidades rocosas.

Lo que ahora mismo conocemos nos permite asegurar que las primeras muestras de lo neolítico se concretan en el equipamiento material: la cerámica siempre acompañada de los elementos líticos característicos (triángulos y, sobre todo, segmentos de doble bisel, algún taladro típico). En 6370 70 (Aizpea III) y $6320 \pm 280$ (Zatoya I) se datan las primeras cerámicas (lisas y alguna impresa) de las estribaciones del Pirineo navarro, fechas que están en consonancia con las primeras manifestaciones del Neolítico aquitano (Roussot-Larroque 1998). Por otro lado, la influencia cardial llega hasta aquí en fechas de alrededor 6200 BP según se deduce de los sitios de Peña Larga, en Rioja Alavesa, en su nivel basal o IV (Fernández Eraso 1997: 161) y de Atxoste, en las estribaciones meridionales de la Llanada, en un nivel que se superpone a un grueso paquete mesolítico previo (Alday 2000: 102). Las recientes y reiteradas dataciones del nivel III superior de Mendandia a fines del octavo milenio (en $7210 \pm 80$ y $7180 \pm 45$ ) plantean, sin embargo, una nueva problemática que deberá ser valorada a fondo con la contrastación de todos los datos arqueológicos que el yacimiento mismo y los de su entorno proporcionen.

En todo este ámbito occidental de la cuenca los sistemas económicos de explotación del medio están en consonancia con el entorno de la ubicación de los asentamientos. En la mayoría se siguen practicando actividades de caza y recolección, mientras que la domesticación más antigua se documenta en el nivel IV de Peña Larga que ha acogido a "grupos de pastores transhumantes" con una cabaña ganadera variada, compuesta ya por Ovis/Capra, cerdo y vacuno, y que además practicaban la caza y la recolección de vegetales silvestres (Fernández Eraso 1997: 172-173). 
Frente a este panorama bien conocido de ocupaciones de abrigos y cuevas, conviene recordar las perspectivas abiertas por recientes identificaciones de asentamientos de aire libre. Se reconoce que el establecimiento en pequeñas aldeas al aire libre supone un cambio cualitativo definitivo en el progreso del proceso de neolitización, tanto en las tácticas de explotación del medio-ya preferentemente productoras-como de estructuración social -grupos más grandes y complejos-; se eligen para esos emplazamientos territorios menos compartimentados (en fondos de valles abiertos o en altiplanos) cuyos campos de cultivo se instalarían en las inmediaciones del propio asentamiento.

Este proceso se ha venido situando tradicionalmente en el transcurso del sexto milenio BP, particularmente en su segunda mitad que es cuando se extenderán de forma generalizada los sitios de aire libre articulándose en redes bastante tupidas que coinciden en el tiempo, especialmente en la cuenca alta del Ebro, con la introducción del nuevo ritual funerario megalítico. Sin embargo, recientes investigaciones empiezan a reconocer asentamientos de superficie más antiguos, asociados a veces a sepulturas en fosa, con fechas del séptimo milenio que nos deben hacer reflexionar sobre la dinámica, la cronología y la profundidad de esta mutación. En la cuenca del Ebro se pueden citar ya algunos casos de estructuras de este tipo utilizadas entre el último tercio del séptimo milenio y mediado el sexto BP: así, el de la Lámpara (Soria), en la alta cuenca del Jalón, es un espacio de hábitat asociado a una sepultura individual en fosa que se ha datado en el último tercio del séptimo milenio BP (Rojo y Kunst 1999). En Navarra, se conocen los de Paternanbidea en la Cuenca de Pamplona y de los Cascajos en Tierra Estella, que son, así mismo, casos en que se combinan estructuras de habitación y de enterramiento -en fosas excavadas en el suelo-similares al anterior, y cuya cronología absoluta está en estos momentos gestionándose, pero los ajuares cerámicos de los Cascajos (con decoraciones impresas, incisas, de boquique, acanaladas,...) se documentan en el conjunto de la cuenca del Ebro desde el Neolítico antiguo con fechas que, remontándose a la segunda mitad del séptimo milenio, pueden perdurar hasta mediados del sexto (García Gazólaz y Sesma 1999: 349-350). En Zaragoza, en la confluencia del Segre en el Ebro se encuentra el asentamiento de Riols I que ha entregado varios fondos de cabaña circulares, con una datación para su base de 6040 \pm 100 BP y otras de fines del sexto milenio para la fase final de la ocupación (Royo y Gómez 1992); en la orilla opuesta, el poblado y necrópolis de la Mina Vallfera se consideró en su momento (Royo 1984) como la derivación más meridional e interior de la cultura de los sepulcros de fosa catalanes.

Del mismo modo, en áreas costeras mediterráneas se citan bastantes asentamientos al aire libre, algunos de los cuales remontan al Neolítico antiguo de ambiente cardial: en Provenza, además de Leucate (Aude), se da para aquella fase el establecimiento de Baratin (Vaucluse) datado en 6600 \pm 140 (Vaquer 1998: 418-420); en Cataluña, los de Plansallosa y la Draga proporcionan dataciones desde mediados del séptimo milenio a mediados del sexto (Bosch et alii 1999; Bosch, Chinchilla y Tarrús 1999). Más al sur, en el sector central del Mediterráneo peninsular, se consideran neolíticos algunos emplazamientos al aire libre aunque los datos manejados son, por ahora, endebles a falta de investigaciones en profundidad; pero ello no impide sugerir que "la preferencia por las cuevas como lugar de hábitat (desde el Neolítico antiguo cardial) podría ser más aparente que real dados los problemas que plantea la localización de yacimientos en áreas erosionadas o sobre tierras bajas aluviales" (Martí y Juan-Cabanilles 1998: 833). De ser así, el entramado poblacional se revelaría como bastante más complejo de lo que ahora conocemos y desde luego, incluso en el interior del paradigma cardial y del modelo de dualidad de poblaciones, habría que buscar explicaciones funcionales para justificar la variabilidad de asentamientos (al binomio de cuevas/aire libre habrá que añadir también el uso de abrigos previamente ocupados por grupos mesolíticos, tal como ocurre en La Falaguera) o de territorios de explotación y uso (accidentados o de tierras bajas, costeros o de interior, etc.). 


\section{REFLEXIONES PARA UNA INTERPRETACIÓN: LA PRECARIEDAD DE LOS MODELOS}

"Si formulamos las teorías antes de realizar las investigaciones, corremos el riesgo de perdernos en la teorías y manipular los hechos" (J.M. de Barandiarán, 29/9/1979).

Las nuevas investigaciones van añadiendo a lo hasta ahora conocido secuencias, equipamientos y fechas que revelan, a nuestro parecer, una notable complejidad del proceso de neolitización en las diversas áreas peninsulares, fenómeno del que no es ajena en absoluto la cuenca del Ebro. Inquietan, sin embargo, los repetidos intentos de mantener modelos explicativos unitarios sobre grandes espacios aún a riesgo de tener que invalidar los datos que podrían poner aquéllos en peligro.

Centraremos nuestra reflexión sobre esta tendencia a discriminar datos para mantener la teoría: por ejemplo, cuando se formaliza a partir del caso de Cendres el concepto de los "contextos arqueológicos aparentes" (C.A.A.) del que se servirán sus presentadores para decidir qué dataciones $\mathrm{C} 14$ de otros sitios son aceptables o no; o cuando, más en general, se cuestiona la validez de la sedimentación holocena. Por otra parte, algún yacimiento recientemente publicado parece que complica bastante la lógica del "modelo de los dos mundos" (así llamado por Schuhmacher y Weniger 1995: 93 el conocido modelo dual) que utiliza el paradigma cardial como motor de neolitización y que, concebido por J. Fortea en 1973 para explicar la variabilidad de equipo y asentamientos en el Neolítico del Mediterráneo español, ha ido ampliando su aplicación a otros territorios, por ejemplo a Aragón (Baldellou, Mestres, Martí y Juan-Cabanilles 1989) e, incluso, al conjunto de la neolitización peninsular (Martí y Juan-Cabanilles 1997 y 2000).

Se ha reconocido honestamente (Bernabeu, Pérez Ripoll y Martínez Valle 1999: 594) la escasa o nula convicción de las dataciones (efectivamente erróneas por mal localizadas en relación a los niveles de ocupación) de algunas muestras de Cendres lo que, en su argumentación, muestra "claramente el comportamiento errático de la cronología radiocarbonométrica asociada a los contextos arqueológicos aparentes". Efectivamente son varios los problemas que, al parecer, plantea la estratigrafía de ese yacimiento alicantino (ibídem): a) "los procesos de origen antrópico" (fosas) que generan movimientos verticales de los materiales, como debe suceder con la datación de 6280 BP para un hueso de Ovis aries de lo más profundo de la estratigrafía neolítica (CC1); b) la mezcla de carbones procedentes de niveles precerámicos y cerámicos: los de Pinus nigra de cronología "efectivamente pleistocena" (20430 BP) que se recogieron en el nivel suprayacente (CC2); c) la datación holocena de un carbón de Quercus, pero "demasiado elevada (en 8310 BP) en relación con lo esperado" de la base de la secuencia neolítica de CC1, lo que "deja abierta la posibilidad de que los últimos estadios precerámicos de la cueva, poco documentados (¿no identificados en la excavación?) debido a los constantes procesos de erosión, penetren dentro del Holoceno, en un momento relacionable con las industrias del Epipaleolítico microlaminar"; y d) la situación intermedia o de "modelo mixto" en los datos tafonómicos de la fauna recuperada en los conjuntos $\mathrm{CC} 1$ a CC3, correspondientes al Neolítico cardial, que se explica por el "contacto entre los momentos cerámicos y precerámicos de sus respectivas secuencias".

Aceptamos, desde luego, con Bernabeu, Pérez-Ripoll y Martínez Valle que los contextos arqueológicos aparentes son "asunto de la mayor gravedad e imposible de ignorar" y es evidente que su llamada de atención sobre el caso efectivo de Cendres suscita una cautela generalizada ante otros muchos niveles y yacimientos. Pero nos parece excesivo generalizar tal sospecha de apariencia estratigráfica a todo yacimiento cuya datación no resulte acorde con lo determinado en la modelización teórica correspondiente (el caso de Forcas II, por ejemplo), puesto que se estaría dando curso a un argumento de apariencia lógica -pero de hecho un tanto circular (por excesivamente inductivo)-con este desarrollo: a, las fechas tienen un comportamiento errático cuando no convienen a lo que se supone o espera; $b$, el comportamiento errático de una fecha se asocia a un C.A.A.; c, luego de toda fecha no conveniente (¿no prevista?) se decide el carácter A. de un C.A. Cuando la argumentación silogística (deductiva) sería prácticamente la inversa: a, el arqueólogo determina (mediante 
criterios arqueológicos propios) que el depósito x es un C.A.A.; b, todo C.A.A. genera fechas erráticas; c, luego, las fechas entregadas por el depósito x deben ser reconocidas como erráticas.

Además, las argumentaciones de orden sedimentológico y estructural que toman esos tres especialistas de reflexiones de P. Fumanal (Fumanal 1995), en el sentido de que a partir del 7500/6000BP se activan procesos denudativos de laderas y se producen movimientos de masas que se integrarán en sedimentos de cuevas y abrigos -a más de otras alteraciones estratigráficas producidas por los propios usuarios de los asentamientosparecen razones que deben invalidar -0 , cuando menos, someter a severa reticencia-la aceptación de cualquier secuencia del Holoceno; y van a ser estas referencias las que se irán aduciendo para rechazar cuantos datos contradigan un modelo determinado (y no sólo el cardial, sino cualquiera otro que se pueda formular como alternativa). Así, por ejemplo, y llevando a sus últimas consecuencias (o al ridículo, si se quiere) el argumento de la existencia generalizada de C.A.A. en cuevas y abrigos con depósitos holocenos, y tomando como ejemplo la propia cueva de Cendres, podemos preguntarnos:

— si efectivamente se han detectado en Cendres alteraciones estratigráficas lo suficientemente acentuadas como para que se produzcan deslizamientos alteraciones e intrusiones en sentido descendente y ascendente de huesos y de carbones ¿hay realmente seguridad de que el resto de los componentes del registro arqueológico de ese yacimiento esté en su sitio?;

— o, más aún, si para rechazar los datos que no convienen de Forcas II se aduce que la cerámica cardial del nivel V de este sitio aragonés puede proceder del inmediatamente posterior (del VI), ¿no ha podido suceder lo mismo en Cendres (o en Or si vamos al caso) y si generalizamos la sospecha, como parece que sería lo coherente, en todos los yacimientos del Holoceno? En cuyo caso, el prolijo cuadro que se ha planteado con la evolución de los estilos decorativos de la cerámica neolítica del arco mediterráneo peninsular ¿no podría estar asentado en el azar derivado de los procesos postdeposicionales que habrían afectado a todos los yacimientos que fueron muestreados?

Este mismo caso de Forcas nos parece interesante para resaltar el sentido de las discusiones derivadas del análisis pormenorizado de su estratigrafía y las posturas que su secuencia ha suscitado entre diferentes especialistas. Su ubicación en el Prepirineo oscense inauguró el conocimiento de depósitos mesolíticos importantes en este territorio. Hasta el momento de su descubrimiento, se había utilizado la ausencia de esa referencia cultural para justificar la neolitización ex novo de todo este ámbito territorial (así Rodanés 1996). Excavado recientemente, Forcas entrega una secuencia mesolítica impecable (Utrilla y Mazo 1997) a la que suceden

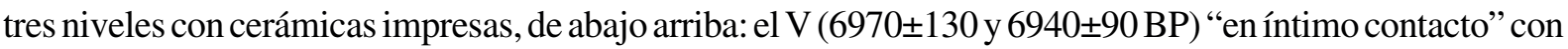
el infrapuesto IV (mesolítico) con cerámicas cardiales y mezclados geométricos abruptos y de doble bisel; el VI (6900 \pm 45 BP) con cerámicas impresas -alguna cardial-y geométricos de doble bisel; e, intermediando el estéril nivel VII, el VIII (6680ะ190 BP) ya con ovicápridos domésticos (antes sólo había fauna salvaje), hojas con lustre, taladros de sílex y cerámicas poco representativas, estando ahora ausentes los geométricos. Frente a estos hechos, las reacciones son variadas entre los neolitistas:

- alguno (J. Bernabeu recurriendo a la filosofía de los C.A.A.: Bernabeu 2000) apunta una doble posibilidad para explicar-rechazándolas-las que él considera altas fechas del nivel V: que el único carbón que se utilizó como muestra procedería del infrapuesto nivel IV o que las cerámicas (cardiales en alta proporción) habrían bajado del suprayacente VI. A lo que, de cualquier forma, ha de hacerse notar que incluso admitiendo error en las fechas del nivel V (6970 y 6940) por deslizamiento no controlado de ¡sólo las cerámicas cardiales!, sigue en pie la que sitúa el VI en 6900 por lo que la discusión se plantea exclusivamente por poco más de cincuenta años.

- otros (Martí y Juan-Cabanilles 2000) aceptan la existencia de un sustrato epipaleolítico "aunque no sea éste el que explica la aparición del foco neolítico puro de Chaves” (¿por qué?) y sugieren-así mismo 
y "sin menoscabo de esta secuencia general"- que el papel de Forcas podría asimilarse al jugado por Tossal de la Roca (Martí y Juan-Cabanilles 1997: 242) (y de la Falaguera) situado en la zona de Or y Sarsa, donde lo cardial será "la única tradición que se mantendrá... después de haber acabado con la correspondiente al Epipaleolítico" (ibid: 234). "El nuevo nivel neolítico que se anuncia en Forcas II... ¿.puede indicar el final de la tradición epipaleolítica en el yacimiento y su incorporación al Neolítico de nueva planta que representa Chaves en la zona?" (ibid: 242).

— los propios excavadores en diversas ocasiones (Utrilla y Mazo 1997 y 1999; Baldellou y Utrilla 1999) barajan diferentes posibilidades pero apuntan con sensatez los problemas de base que el yacimiento suscita frente al modelo tradicional aceptado: a) son conscientes de las antiguas dataciones de Forcas frente a yacimientos catalanes y, como sitio "aculturado", frente a las propias de aquél (Chaves) al que se atribuye el rol de pionero y difusor de innovaciones en el área geográfica del Alto Aragón (Baldellou y Utrilla 1999: 227); b) optan por un modelo de "aculturación neolítica del poblamiento epipaleolítico que está debajo" en el que los cazadores han aceptado "voluntariamente" la cerámica y han cambiado la técnica del retoque abrupto por la de doble bisel, aunque las estrategias económicas no hayan cambiado..., pero tampoco descartan la "eventualidad" de que las diferencias entre Forcas y Olvena puedan ser explicadas por una diferencia de actividad...(Utrilla y Mazo 1999: 245); y c) parece que asumen una diferencia entre "un Neolítico aculturado" de los niveles V y VI y una situación con economía de producción y unos ajuares "similares a los de Olvena y Chaves" que "encajan mejor" con los "propios de un Neolítico puro" (Utrilla y Mazo 1997: 353).

Al respecto, se nos ocurren las observaciones de que:

— al margen de la presunción que se sugiera ahora de deslizamientos de unos niveles a otros de carbones o cerámicas, en el momento de su excavación la entidad deposicional del yacimiento de Forcas no pareció a los arqueólogos en absoluto alterada por desfases ni inversiones y las series estratificadas de industrias y de dataciones $\mathrm{C} 14$ de los niveles correspondientes ofrecen sendas secuencias absolutamente coherentes.

- aunque se plantee hipotéticamente la posibilidad de algún tipo de alteración de la entidad del nivel V quedan otros dos niveles (los VI y VIII) con cerámicas cuyas fechas denotan una considerable antigüedad.

— si se admite que el nivel VIII es un Neolítico puro - en teoría, por tanto, estímulo neolitizador de poblaciones mesolíticas-, resulta que el supuesto estímulo (el representado en el propio Forcas II y en los sitios de Chaves y Olvena, los más antiguos del Alto Aragón: "Chaves se erigiría así en un ejemplo paradigmático de una instalación precoz, responsable de la primera difusión de prácticas neolíticas en el Prepirineo altoaragonés, en primer lugar como foco de aculturación (Forcas) y posteriormente como centro generador de expansiones coloniales sucesivas (yacimientos epicardiales contiguos)" aseguran Baldellou y Utrilla 1999: 226) es posterior al efecto estimulado cuando, en lógica, debería ser anterior.

A nuestro entender, si hay una secuencia que parece coherente, jalonada por unas fechas de radiocarbono no absolutamente rechazables (al menos no todas -nosotros no tenemos argumentos para rechazar ni una de ellas-), ¿por qué no aceptar los hechos y recurrir a explicaciones más sencillas? Desde luego, y sin entrar en cuestiones interpretativas, no nos parece acertada la equivalencia de la secuencia de Forcas con las de Tossal de la Roca o La Falaguera. En Tossal de la Roca (Cacho et alii 1995) y La Falaguera (García Puchol y Aura 2000) hay una cesura aparente entre los niveles mesolíticos y los neolíticos ya que aquéllos se asemejan en ajuares a los de Cocina I y sus fechas coinciden con las de los correspondientes niveles de los abrigos del Bajo Aragón. 
En cambio, en Forcas se halla toda la secuencia mesolítica, incluyendo la fase "transicional" datada (desgraciadamente con un margen de error muy amplio) en poco más de cien años más vieja (7090 340 ) que la más antigua de cerámicas cardiales, habiéndose recogido precisamente en ese mismo nivel IV -dotado de un geometrismo basado en trapecios y triángulos de retoque abrupto- una plaqueta grabada con motivos geométricos comparable con las de Cocina II. Tampoco parece lógica la posibilidad enunciada por Martí y JuanCabanilles -e indirectamente por los excavadores del yacimiento- de que el nivel VIII de Forcas indicaría el final de la tradición epipaleolítica en el yacimiento y su incorporación al Neolítico "de nueva planta" representado en Chaves, ya que no en balde en Forcas ese Neolítico de nueva planta está precedido por niveles con cerámicas bastante más antiguos y, aunque así fuera, ¿qué vía se concede a los grupos humanos de tradición epipaleolítica?: si es la de su incorporación al Neolítico, se aceptaría su evolución hacia formas productoras en una datación tan antigua como las de Chaves u Olvena (sólo que ya manejaban cerámica desde bastante antes) -por tanto, experimentarían un proceso de neolitización progresivo-; si no, habrá que pensar que se han extinguido o que han emigrado - ¿a dónde?- para continuar con sus propios modos de vida de cazadores/recolectores.

Sin forzar tanto la explicación, al menos desde nuestro punto de vista, podemos ofrecer una doble interpretación del proceso evolutivo de Forcas:

a) reconociendo una secuencia evolutiva lineal o estática, estaríamos ante un ejemplo magnífico de neolitización progresiva: de lo más sencillo, sobre una base del Mesolítico final se produce la aceptación de determinados bienes materiales (las cerámicas cardiales) por parte de unas poblaciones a las que esa posesión no altera en nada su organización técnica y económica; a lo más complejo, la modificación en el transcurso de un par de siglos de las formas de explotación del medio con la introducción de técnicas productivas y, obviamente, la utilización de los instrumentos adecuados para llevarlas a cabo, o

b) proponiendo una opción multilineal más dinámica, optaríamos por considerar el abrigo de Forcas como un refugio excelente, ubicado en un medio geográfico de posibilidades explotativas atrayentes para grupos que sucesivamente lo utilizaron en el tiempo. En cuyo caso, las actividades que se desarrollan en él son el más importante factor desequilibrante de la variabilidad en el equipamiento lítico y cerámico, al margen del grado de asunción, si es que eso se ha de discutir, de los principios del Neolítico por parte de sus usuarios y de su papel en el proceso de neolitización en el Alto Aragón.

En resumen, es claro que haya de admitirse en este caso y en comparación con asentamientos como Chaves o la cueva del Moro de Olvena una dualidad, pero no necesariamente de poblaciones, sino de tipos de asentamiento (los más permanentes y los de posible uso estacional) y de territorios de explotación (adecuados a una explotación agropastoril o suficientes para el sustento mediante caza/recolección de grupos más reducidos incluso en etapas en las que la neolitización en marcha ya es patente en algunos elementos del registro material).

Habrá que señalar, además, que estamos ante un caso por ahora único, pero que, si la investigación se intensifica, es seguro que será acompañado por bastantes más si se toman como punto de referencia las concentraciones tan llamativas que se están controlando últimamente en áreas más occidentales de la misma cuenca del Ebro. En estos ámbitos se utilizaron como refugio tanto abrigos con viseras bien desarrolladas (Mendandia, por ejemplo) -de fácil detección por parte de los prospectores-como recovecos o entrantes poco definidos -y por tanto más difíciles de localizar-en cantiles rocosos (como Atxoste, la Peña o Aizpea) donde probablemente se construirían estructuras acopladas que ampliarían la extensión del espacio protegido. 


\section{UN COMENTARIO DE CONCLUSIÓN}

Al fin de estas reflexiones suscitadas por las dataciones y estratigrafías del Bajo Aragón y del resto de la cuenca del Ebro, hemos de reiterar nuestras opiniones y recordar también nuestras inseguridades.

\# Distamos mucho de poder manejar una información completa y/o dotada de efectivos y calidad equiparables: buena parte de las referencias habituales del frente mediterráneo o de Aragón se asientan en trabajos e identificaciones antiguos, en prospecciones someras o en excavaciones en curso con datos todavía poco elaborados.

A pesar del desapego que bastantes investigadores muestran hacia ello, es imprescindible recordar que faltan secuencias cronológicas completas del proceso, sobre todo en el frente mediterráneo. En Aragón, y en general en toda la cuenca del Ebro, tal carencia está subsanándose en estos últimos años y es precisamente allí donde los modelos preestablecidos deberían ser reconducidos para que se adecuaran a la realidad constatada en el registro arqueológico. La secuencia de Forcas parece evidenciar una evolución progresiva de las poblaciones altoaragonesas hacia el Neolítico que culminará con los asentamientos permanentes tipo Chaves. En el Bajo Aragón se constata curiosamente un vacío de casi quinientos años (cuando en territorios costeros se producen las primeras ocupaciones neolíticas) en las dataciones entre el inicio de la transición representado en el nivel 4 de Botiquería y las primeras cerámicas controladas pertenecientes a conjuntos materiales muy variados que, en cronología y en cuantificación de los motivos decorativos (si es que ello sirve para algo, en especial en lotes tan exiguos), se acomodarían a lo epicardial de áreas costeras.

\# Nos resulta más cómodo -como teoría de interpretación de los datos hoy aquí disponibles- reconocer una diversidad de asentamientos y paisajes (por tanto de actividades, o sea de soluciones concretas a las necesidades planteadas en cada sitio/zona) que una dualidad de poblaciones.

Sin sentirnos especialmente implicados en los dos modelos alternativos al de los dos mundos -el modelo del "mundo único" y el modelo de"mosaico" (que explican Schuhmacher y Weniger 1995: 93-94)no nos son incómodas sus propuestas de explicación de estos procesos culturales y aceptaríamos, con matices, que nuestra interpretación de los datos del Bajo Aragón haya sido incluida en el epígrafe (Martí y Juan-Cabanilles 1997: 223) "funcionalidad y estacionalidad en la explicación de la diversidad". Y volveremos a recordar (Barandiarán y Cava 1992: 194) que la diferenciación entre lo que se ha definido como "lo neolítico puro" " "lo epipaleolítico neolitizado" nos parece más cuantitativa que cualitativa: están presentes la mayoría (mejor o peor expresada) de los elementos de cultura material en todas partes y son similares las potencialidades de su aplicación, pudiéndose referir las diferencias de unos yacimientos y otros en cuanto a sistemas económicos, ergonómicos, simbólicos o de ocupación (presencia/ausencia de especies animales o vegetales domesticadas, abundancia/escasez o diversidad de cerámica e industria ósea, calidad técnica o composición tipológica de la lítica, expresión figurada de diferentes temas y tratamientos tanto en cerámicas como en paneles rupestres, asentamientos ex novo o continuidad estratigráfica con respecto a periodos anteriores) a adaptaciones -las respuestas de optimización de un equipamientoal aprovechamiento de situaciones, recursos y paisajes de los sitios y territorios concretos.

Los yacimientos son el resultado de las ocupaciones humanas sucesivas que desarrollan allí unas actividades determinadas que pueden no corresponderse plenamente con sus habilidades potenciales sino, más bien y en lógica, adaptarse a las condiciones del medio. En su estudio de la Grotte Lombard, a unos veinte kilómetros de distancia de la costa provenzal, D. Binder propone una especialización funcional en la caza de una comunidad neolítica asentada estacionalmente en un entorno poco favorable -por accidentado-para el desarrollo de la agricultura. El único resto de oveja recuperado en el registro 
faunístico se ha interpretado como la provisión de carne llevada allí en tanto no se produzca el abastecimiento por caza de ungulados salvajes, actividad que se refleja en el equipamiento material en forma de proyectiles líticos (Binder et alii 1991).

Parece que este modelo de diversidad funcional dentro del ámbito cardial ha gustado y se rastrea en multitud de casos en toda la Península Ibérica (Martí y Juan-Cabanilles 1997: 226-228) incluso desde el Neolítico antiguo; ¿por qué tal modelo interpretativo no puede hacerse extensivo a otros territorios como, por ejemplo, el Alto Aragón o el Bajo Aragón? Muchos de los argumentos ofrecidos para resaltar las diferencias en la cultura material, especialmente en lo lítico, carecen de fuerza: la disponibilidad de la materia prima en calidad y en tamaño de los nódulos puede incidir en las no llamativas diferencias en el tamaño relativo de las industrias; la práctica de actividades más o menos intensas de talla en el sitio (o, al menos en la parte excavada -se puede tallar en el exterior del asentamiento; es curioso que en cuevas que parecen de ocupación permanente como Or o Chaves los restos de talla son bastante menos habituales que en los abrigos de uso más eventual del Bajo Aragón, por ejemplo-) puede ser la causa de la no conservación de algunos elementos que nos parecen determinantes en la identificación de grupos (por ejemplo, los microburiles); y algunos tipos concretos que se consideran definitorios de distintas culturas (los taladros y los geométricos de doble bisel) están presentes, aunque en diferentes proporciones, en ambas comunidades: la referencia a intercambios en los dos sentidos (Juan-Cabanilles 1992: 262) no nos parece suficiente (por ejemplo, para explicar lo segmentos de doble bisel desde los estadios más antiguos de Or) y optamos, una vez más, por el argumento de que las actividades desarrolladas en los sitios incidirán en la elección adecuada de una u otra modalidad de instrumento.

\# Constatamos una interacción cultural entre territorios de la cuenca del Ebro y otros externos que se articulan con ellos. Partiendo de que durante el octavo milenio BP existe un referente cultural común a toda la cuenca del Ebro (y también en amplias áreas del suroeste de Europa), se advierten en este territorio cruces de influencias con otros externos - del área continental y del frente mediterráneo-que diseñarán diferencias en los ritmos de adopción y en la variabilidad de adaptaciones a lo largo del proceso de transición mesoneolítico en los grupos más próximos. En este sentido, los asentamientos del Bajo Aragón y del prepirineo oscense siguen un modelo similar a los enclavados en el frente mediterráneo con una evolución del Mesolítico que desembocará en la adopción de técnicas y actitudes neolíticas. La dualidad de asentamientos se hace llamativa por la riqueza y amplitud de algunos sitios (Chaves, Or o Cendres) frente a la continuidad en la utilización de abrigos y cuevas menores que han sido ocupadas desde el Mesolítico (Forcas, Cocina, La Falaguera, Tossal de la Roca o los abrigos del Bajo Aragón).

\# El Mesolítico, que está dotado de un apreciable "dinamismo", actúa como base común para el proceso poblacional y/o cultural de la cuenca del Ebro.

Los sistemas de ocupación del territorio - densos ya en áreas de interior-y de explotación integral de los recursos por los mesolíticos son muy diferentes a los practicados por los grupos del Tardiglaciar y primeros compases del Holoceno cuando se depositan los niveles propios del Aziliense y de las industrias inmediatamente sucesoras; el componente industrial experimenta así mismo un cambio determinante, especialmente en el comienzo del octavo milenio BP, cuando se introducen con fuerza las industrias de trapecios. Al contrario, nos parece que ni en el sentido tecnotipológico ni en la densidad y distribución de las poblaciones el Neolítico marca ruptura alguna con lo inmediatamente precedente, sino una acomodación funcional de ciertos artefactos (láminas simples o levemente retocadas o, en algunos casos, los geométricos) y de unos sitios a las nuevas necesidades que se plantean: la creación de nuevos tipos industriales es muy restringida y variada su presencia en los yacimientos, pudiéndose explicar por la especialización de los asentamientos. 
La revisión de datos etnográficos de algunos grupos de Nueva Guinea permite a A.J. Ammerman, sorprendido por "la fluidez de la residencia, la circulación abierta de personas en los asentamientos de quienes tienen un modo de vida fundamentalmente sedentario", interpretar los procesos de la transición neolítica europea con afirmaciones (Ammerman 2000) que podemos suscribir: a) "existe una tendencia en los estudios del Neolítico, y en la Prehistoria en general, a equiparar las historias de la vida de los individuos con las historias del lugar"; b) "los hechos demográficos de un individuo determinado muchas veces se distribuyen por el paisaje. Tal vez fuera el caso también en el Neolítico antiguo en muchas partes del Mediterráneo occidental”; y c) "el paisaje neolítico... era sin duda un lugar dinámico". Acogemos plenamente esas reflexiones, pero añadiríamos: ¿por qué se circunscriben al Neolítico?, ¿no son perfectamente aplicables a los grupos mesolíticos precedentes? Efectivamente, el registro arqueológico (lo acabamos de comprobar en el abrigo de Aizpea, en Navarra) (Cava 1997; Barandiarán y Cava 2001) proporciona datos sobre la circulación de tipos industriales, de materias primas líticas o de elementos de adorno a media y larga distancia y el acceso a recursos distintos de explotación estacional (de caza, pesca y recolección de vegetales) que demuestran la notable movilidad de las poblaciones mesolíticas y el "dinamismo" de sus paisajes. La presencia habitual en niveles mesolíticos y neolíticos de conchas marinas procedentes con bastante seguridad del Mediterráneo -las de Collumbella rustica especialmente- y de otros elementos de cultura material en estratigrafías de toda la cuenca del Ebro demuestra que las relaciones, directas o de intercambio, costa-interior no sólo se producen en el tiempo de la llegada del Neolítico-o de los supuestos grupos específicamente neolíticos-a las regiones litorales, sino que existen ya desde el Mesolítico.

\# Son muchas nuestras dudas e incertidumbres frente a la firmeza evidente de los que plantean el modelo dual; por eso seguramente nuestra argumentación parece menos sólida. Obviamente, no nos sentimos indigenistas a ultranza; aceptamos sin problema, por lo evidente, que los estímulos (y los mismos resultados culturales: determinadas especies domésticas vegetales o animales, los modos decorativos en cerámica o la expresión simbólica) son exógenos. Pero nos resulta poco convincente la suposición de la arribada de algunos grupos (que no parecen numerosos, según el registro arqueológico hoy disponible) tan activos como para inducir la neolitización de toda la población preexistente (¿en no mucho tiempo?).

\section{REFERENCIA BIBLIOGRÁFICA}

AGUIRRE, M.; LÓPEZ QUINTANA, J.C. y SÁENZDE BURUAGA, A. (2000): "Medio ambiente, industrias y poblamiento prehistórico en Urdaibai (Gernika, Bizkaia) del Würm reciente al Holoceno medio", Illunzar 98/00, nº 4: 13-38.

ALBERTO, F. y MACHÍN, J. (1985): "Estudio sedimentológico de los materiales de relleno del abrigo de Botiquería dels Moros (Mazaleón)", Bajo Aragón, Prehistoria 6: 51-65.

ALDAY, A. (1995): "Patrones de asentamiento y organización del territorio en Álava durante el Epipaleolítico y el Neolítico", Cuadernos de Sección. Prehistoria-Arqueología, nº 6: 289-316. Sociedad de Estudios Vascos.

- (2000): "El Neolítico en el País Vasco: pensando en la marginalidad", Actas do $3^{\circ}$ Congresso de Arqueologia Peninsular, vol. III: Neolitizaçâo e megalitismo da Península Ibérica: 97-113. ADECAP, Oporto.

AMMERMAN, A.J. (2000): "Retorno a la transición neolítica en Europa", El Paisaje en el Neolítico Mediterráneo. Jornadas Internacionales. Cinc Segles de la Universitat de Valencia, Valencia (preactas sin paginar). 
BALDELLOU, V.; MESTRES, I; MARTÍ, B. y JUAN-CABANILLES, J. (1989): El Neolítico antiguo (Los primeros agricultores y ganaderos en Aragón, Cataluña y Valencia). Diputación de Huesca. Huesca.

BALDELLOU, V. y UTRILLA, P. (1999): "Le Néolithique en Aragon", Le Néolithique du Nord-Ouest méditerrenéen, XXIV Congrès Préhistorique de France, Carcassonne 1994: 225-237.

BARANDIARÁN, I. (1976): "Botiquería dels Moros (Teruel). Primera Fechación Absoluta del Complejo Geométrico del Epipaleolítico Mediterráneo Español”, Zephyrus 26/27: 183-186.

— (1978): "El abrigo de la Botiquería dels Moros. Mazaleón (Teruel). Excavaciones arqueológicas de 1974", Cuadernos de Prehistoria y Arqueología Castellonense 5: 49-138.

BARANDIARÁN, I. y CAVA, A. (1985): "Las industrias líticas del Epipaleolítico y del Neolítico en el Bajo Aragón", Bajo Aragón, Prehistoria V: 49-85.

- (1989): La ocupación prehistórica del abrigo de Costalena (Maella, Zaragoza). Colección Arqueología y Paleontología, no 6, Serie Arqueología Aragonesa. Diputación General de Aragón, Zaragoza.

— (1992): "Caracteres industriales del Epipaleolítico y Neolítico en Aragón: su referencia a los yacimientos levantinos", Aragón/Litoral mediterráneo: intercambios culturales durante la Prehistoria: 181-196. Institución Fernando el Católico, Zaragoza.

BARANDIARÁN, I. y CAVA, A. et alii (2001): Cazadores/recolectores en el Pirineo navarro: el sitio de Aizpea entre 8000 y 6000 años antes de ahora. Veleia, series maior, Universidad del País Vasco, Vitoria.

BENAVENTE, J.A. y ANDRÉS, T. (1990): "El yacimiento neolítico de Alonso Norte (Alcañiz, Teruel). Memoria de las prospecciones y excavaciones arqueológicas de 1984-85", Al-Qannis 1: 2-58.

BERNABEU, J. (2000): “The social and symbolic context of the neolithisation", El Paisaje en el Neolitico Mediterráneo. Jornadas Internacionales. Cinc Segles de la Universitat de Valencia, Valencia (preactas sin paginar).

BERNABEU, J.; PÉREZ RIPOLL, M. y MARTÍNEZ VALLE, R. (1999): "Huesos, Neolitización y Contextos Arqueológicos Aparentes", II Congrés del Neolític a la Península Ibèrica. Universitat de València. Saguntum-PLAV, extra-2: 589-596.

BINDER, D. et alii (1991): Une économie de chasse au Néolithique ancien. La grotte Lombardà Saint-Vallierde-Thiey (Alpes-Maritimes). Monographie du Centre Archéologique nº 5, Editions du C.N.R.S., Paris.

BOSCH, A.; CHINCHILLA, J. y TARRÚS, J. (1999): "La Draga, un poblado del Neolítico Antiguo en el lago de Banyoles (Girona, Catalunya)", II Congrés del Neolític a la Península Ibèrica. Saguntum-PLAV, Extra 2: 315-321.

BOSCH, A. et alii (1999): "El poblado de Plansallosa y la neolitización del valle del Llierca (Pre-pirineo oriental)", II Congrés del Neolític a la Península Ibèrica. Saguntum-PLAV, Extra 2: 329-335.

CACHO, C. et alii (1995): "El Tossal de la Roca (Vall d'Alcalà, Alicante). Reconstrucción paleoambiental y cultural de la transición del Tardiglaciar al Holoceno inicial", Recerques del Museu d'Alcoi 4: 11-101.

CAVA, A. (1994): "El Mesolítico en la Cuenca del Ebro; un estado de la cuestión", Zephyrus 47: 65-91. (1997): "L'abri d'Aizpea. Un facies à trapèzes et son évolution à la fin du Mésolithique sur le versant sud des Pyrénées", Préhistoire Européenne 10: 151-171.

CUCHI, J.A. (1996): "La sedimentología del abrigo dels Secans (Mazaleón. Teruel)", El abrigo de Els Secans (Mazaleón, Teruel). La ocupación del Valle del Matarraña durante el Epipaleolítico y Neolítico Antiguo: 33-37. Al-Qannis. Boletín del Taller de Arqueología de Alcañiz nº 6, Alcañiz.

DE LA RÚA, C.; BARAYBAR, J.P.; IRIONDO, M. e IZAGUIRRE, N. (2001): "Capítulo 16. Estudio antropológico del esqueleto mesolítico de Aizpea", Cazadores/recolectores en el Pirineo navarro: el sitio de Aizpea entre 8000 y 6000 años antes de ahora. (I. Barandiarán, A. Cava et alii).Veleia, series maior, Universidad del País Vasco, Vitoria. 
IGNACIO BARANDIARÁN / ANA CAVA

FERNÁNDEZ ERASO, J. (1997): Excavaciones en el abrigo de Peña Larga (Cripán, Álava). Memorias de yacimientos alaveses $n^{\circ} 4$. Diputación Foral de Álava. Vitoria.

FORTEA, J. (1971): La cueva de la Cocina. Ensayo de cronología del Epipaleolítico (Facies Geométricas). Serie de Trabajos Varios del S.I.P. $\mathrm{n}^{\circ}$ 40. Valencia.

(1973): Los complejos microlaminares y geométricos del Epipaleolítico Mediterráneo español. Memorias del Seminario de Prehistoria y Arqueología no 4, Salamanca.

FUMANAL, P. (1995): "Los depósitos cuaternarios en cuevas y abrigos. Implicaciones sedimentoclimáticas", El Cuaternario del País Valenciano: 115-124. Universidad de Valencia.

GARCÍA-ARGÜELLES, P.; NADAL, J. y FULLOLA, J.M. (1999): "L'Epipaléolithique en Catalogne: données culturelles et paléoenvironnementales", L'Europe des derniers chasseurs. Epipaléolithique et Mésolithique. Peuplement et paléoenvironnement de l'Epipaléolithique et du Mésolithique: 79-85. Actes du 5e Colloque International UISPP, Commission XII. Grenoble 1995.

GARCÍA GAZÓLAZ, J. y SESMA, J. (1999): “Talleres de sílex versus lugares de habitación. Los Cascajos (Los Arcos, Navarra), un ejemplo de neolitización en el Alto Valle del Ebro", II Congrés del Neolític a la Península Ibèrica. Saguntum-PLAV, Extra 2: 343-350.

GARCÍA PUCHOL, O. y AURA, J.E. (2000): “Abric de La Falaguera (Alcoi)”, Catálog Museu Arqueològic Municipal Camil Visedo Moltó, Alcoi: 63-66, Alcoy.

JUAN-CABANILLES, J. (1992): "La neolitización de la vertiente mediterránea peninsular. Modelos y problemas", Aragón/Litoral mediterráneo: intercambios culturales durante la Prehistoria: 255-268. Institución Fernando el Católico, Zaragoza.

LÓPEZ, P. (1992): “Análisis polínicos de cuatro yacimientos arqueológicos situados en el Bajo Aragón”, Aragón/Litoral mediterráneo: intercambios culturales durante la Prehistoria: 235-242. Institución Fernando el Católico, Zaragoza.

LÓPEZ, P. y LÓPEZ, J.A. (1996): “Análisis paleopalinológico del yacimiento de "Els Secans”: dinámica de la vegetación durante el Cuaternario", El abrigo de Els Secans (Mazaleón, Teruel). La ocupación del Valle del Matarraña durante el Epipaleolítico y Neolítico Antiguo. Al-Qannis. Boletín del Taller de Arqueología de Alcañiz no 6: 84-89, Alcañiz.

LÓPEZ, P.; LÓPEZ, J.A. y SÁNCHEZ, J.J. (1991): “Análisis polínico del yacimiento de Botiquería (Mazaleón, Teruel)", Trabajos de Prehistoria 48: 395-403.

MARTÍ, B. y JUAN-CABANILLES, J. (1997): "Epipaleolíticos y neolíticos: población y territorio en el proceso de neolitización de la Península Ibérica", Espacio, Tiempo y Forma, Serie I, Prehistoria y Arqueología 10: 215-264.

MARTÍ, B. y JUAN-CABANILLES, J. (1998): “XIV. L'Espagne méditerranéenne: Pays Valencien et région de Murcie", Atlas du Néolithique européen. L'Europe occidentale (dir. J. Guilaine). E.R.A.U.L. 46: 825-870.

(2000): "Epipaleolíticos y neolíticos en la Península Ibérica del VII al V milenio A. de C. Grupos, Territorios y procesos culturales", El Paisaje en el Neolítico Mediterráneo. Jornadas Internacionales. Cinc Segles de la Universitat de Valencia, Valencia (preactas sin paginar).

MAZO, C. y MONTES, L. (1987): "La cueva del Llop (Mazaleón, Teruel)", Caesaraugusta 64: 119-134. (1992): "La transición Epipaleolítico-Neolítico antiguo en el abrigo de El Pontet (Maella, Zaragoza)", Aragón/Litoral mediterráneo: intercambios culturales durante la Prehistoria: 243-254. Institución Fernando el Católico, Zaragoza.

MAZO, C.; MONTES, L.; RODANÉS, J.M. y UTRILLA, P. (1987): Guía arqueológica del valle de Matarraña. Guías Arqueológicas de Aragón no 3. Diputación General de Aragón, Zaragoza.

MONTES, L. (1996): "El IV milenio en el Bajo Aragón”, I Congrés del Neolític en la Península Ibèrica. Gavà-Bellaterra 1995. Rubricatum 1: 757-766. 
A PROPÓSITO DE UNAS FECHAS DEL BAJO ARAGÓN: REFLEXIONES SOBRE EL MESOLÍTICO Y EL NEOLÍTICO...

PALLARÉS, M. y MORA, R. (1999): "Organizational strategies of hunter-gatherer communities in the 9th millennium BP along the Eastern Pyrenees", L'Europe des derniers chasseurs. Epipaléolithique et Mésolithique. Peuplement et paléoenvironnement de l'Epipaléolithique et du Mésolithique: 65-71. Actes du 5e Colloque International UISPP, Commission XII. Grenoble 1995.

PÉREZ RIPOLL, M. (1992): Marcas de carnicería, fracturas intencionadas y mordeduras de carnívoros en huesos prehistóricos del Mediterráneo español. Instituto de Cultura "Juan Gil-Albert", Alicante.

RODANÉS, J.M. (1988): "Excavaciones arqueológicas en el abrigo dels Secans (Mazaleón, Teruel). Primera campaña", Kalathos 7-8: 25-43.

_ (1996): "La economía prehistórica en Aragón”, Historia de Aragón. II. Economía y Sociedad: 23-41. Institución Fernando El Católico, Zaragoza.

RODANÉS, J.M.; TILO, M.A. y RAMÓN, N. (1996): El abrigo de Els Secans (Mazaleón, Teruel). La ocupación del Valle del Matarraña durante el Epipaleolítico y Neolítico Antiguo. Al-Qannis. Boletín del Taller de Arqueología de Alcañiz no 6, Alcañiz.

RODANÉS, J.M. y RAMÓN, N. (1995): “El Neolítico antiguo en Aragón: hábitat y territorio", Zephyrus 48: 101-128.

ROJO, M.A. y KUNST, M. (1999): "La Lámpara y la Peña de La Abuela. Propuesta secuencial del Neolítico Interior en el ámbito funerario", II Congrés del Neolític a la Península Ibèrica. Saguntum-PLAV, Extra 2: 503-512.

ROUSSOT-LARROQUE, J. (1998): “Le sud-ouest de la France”, Atlas du Néolithique européen. L'Europe occidentale (dir. J. Guilaine). E.R.A.U.L. 46: 689-761.

ROYO, J.I. (1984): "Excavaciones arqueológicas en el Barranco de la Mina Vallfera. Mequinenza, Zaragoza", Boletín del Museo de Zaragoza $\mathrm{n}^{\circ}$ 3: 5-22.

ROYO, J.I. y GÓMEZ, F. (1992): "Riols I: un asentamiento neolítico al aire libre en la confluencia de los ríos Segre y Ebro", Aragón/Litoral mediterráneo: intercambios culturales durante la Prehistoria: 297-308. Institución Fernando el Católico, Zaragoza.

SCHUHMACHER, T.X. y WENIGER, G.C. (1995): "Continuidad y cambio. Problemas de la neolitización en el este de la Península Ibérica", Trabajos de Prehistoria 52/2: 83-97.

SEBASTIÁN, A. (1988): "Nuevos datos sobre la cuenca media del río Guadalope: el abrigo del Barranco Hondo y el abrigo del Ángel", Teruel 79-II: 77-92.

STUIVER, M y REIMER, P.J. (1993): "Extended 14C data base and revised CALIB radiocarbon age calibration program", Radiocarbon 35: 215-230.

TOMÁS, J. y VALLESPÍ, E. (1960): "Excavaciones en "La Apotequería dels Moros" (Mazaleón)", Caesaraugusta 15/16: 205-206.

UTRILLA, P. (2000): "Epipaleolíticos y neolíticos en el valle del Ebro", El Paisaje en el Neolítico Mediterráneo. Jornadas Internacionales. Cinc Segles de la Universitat de Valencia, Valencia (preactas sin paginar).

UTRILLA, P. y ÁLVAREZ, A. (1985): "Excavaciones en la cueva de los Toros (Cantavieja, Teruel). Campaña de 1984", Bajo Aragón. Prehistoria VI: 9-30.

UTRILLA, P.; CAVA, A.; ALDAY, A.; BALDELLOU, V.; BARANDIARÁN, I.; MAZO, C. y MONTES, L. (1998): "Le passage du Mésolithique au Néolithique ancien dans le bassin de l'Ebre (Espagne) d'après les datations C14", Préhistoire Européenne 12: 171-194.

UTRILLA, P. y MAZO, C. (1997): "La transición del Tardiglaciar al Holoceno en el Alto Aragón: los abrigos de las Forcas (Graus, Huesca)", II Congreso de Arqueología Peninsular, t. I: 349-365. Zamora. -(1999): "Les abris de Las Forcas (Graus, Huesca). La transition de l'Epipaléolithique au Néolithique ancien", Le Néolithique du Nord-Ouest méditerrenéen, XXIV Congrès Préhistorique de France, Carcassonne 1994: 239-246. 
VALLESPÍ, E. (1957): "Yacimientos líticos en el río Matarraña", IV Congreso Arqueológico Nacional: 65-70.

(1959): Bases arqueológicas para el estudio de los talleres de sílex del Bajo Aragón. Universidad de Zaragoza, Tesis Doctoral.

- (1960): "Excavaciones en los yacimientos líticos de "El Sol de la Piñera" y "El Serdá", en Fabara (Zaragoza). Memoria de la primera campaña", Caesaraugusta 15/16. pp.19-39.

VAQUER, J. (1998): “VIII. Le Midi méditerranéen de la France”, Atlas du Néolithique européen. L'Europe occidentale (dir. J. Guilaine). E.R.A.U.L. 46: 413-500.

ZAPATA, L. (2001): "Capítulo 15. El uso de los recursos vegetales en Aizpea (Navarra, Pirineo occidental): la alimentación, el combustible y el bosque", Cazadores/recolectores en el Pirineo navarro: el sitio de Aizpea entre 8000 y 6000 años antes de ahora.(I. Barandiarán, A. Cava et alii).Veleia, series maior, Universidad del País Vasco, Vitoria. 


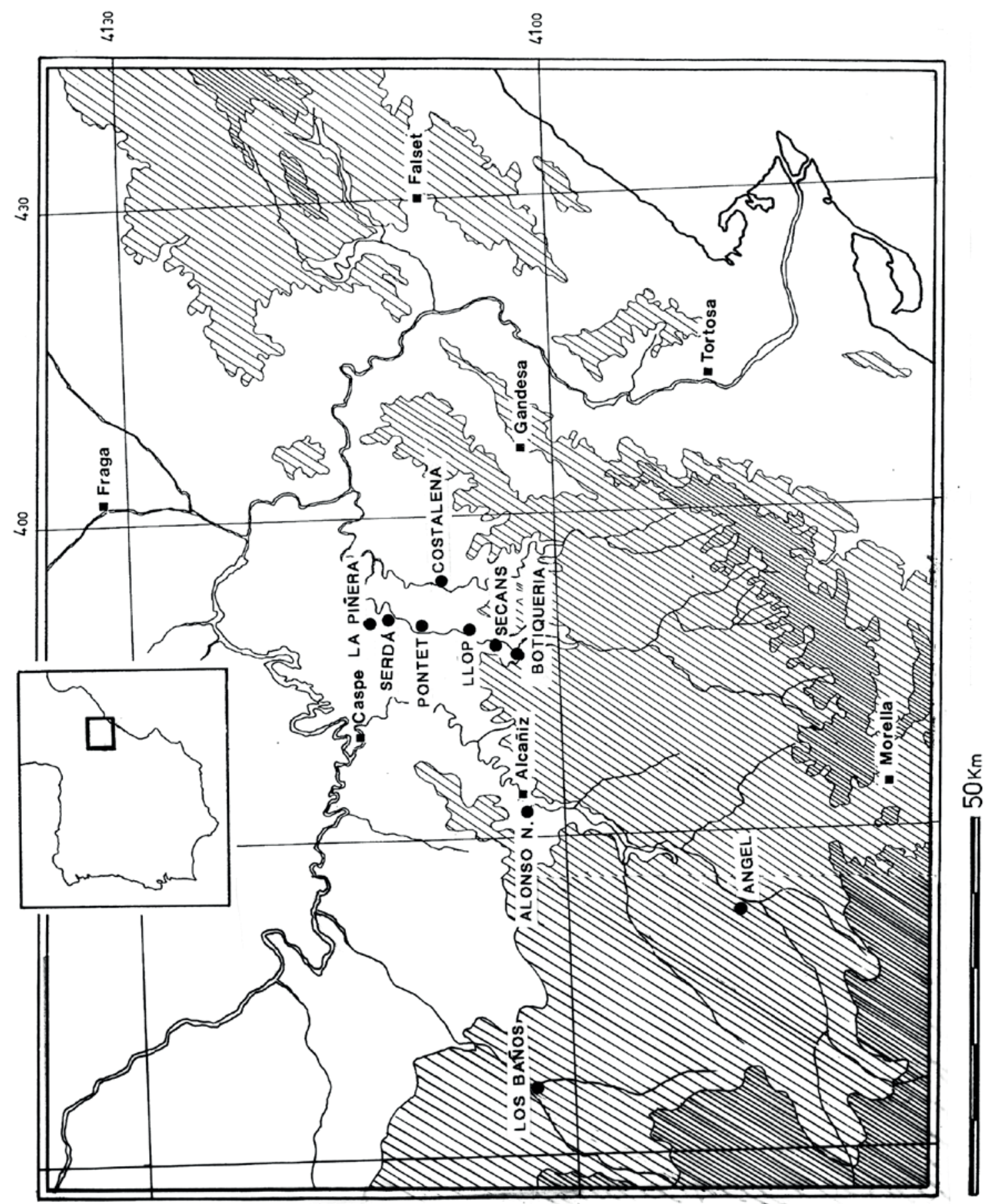

$\underset{\bar{\sigma}}{\stackrel{0}{0}}$ 


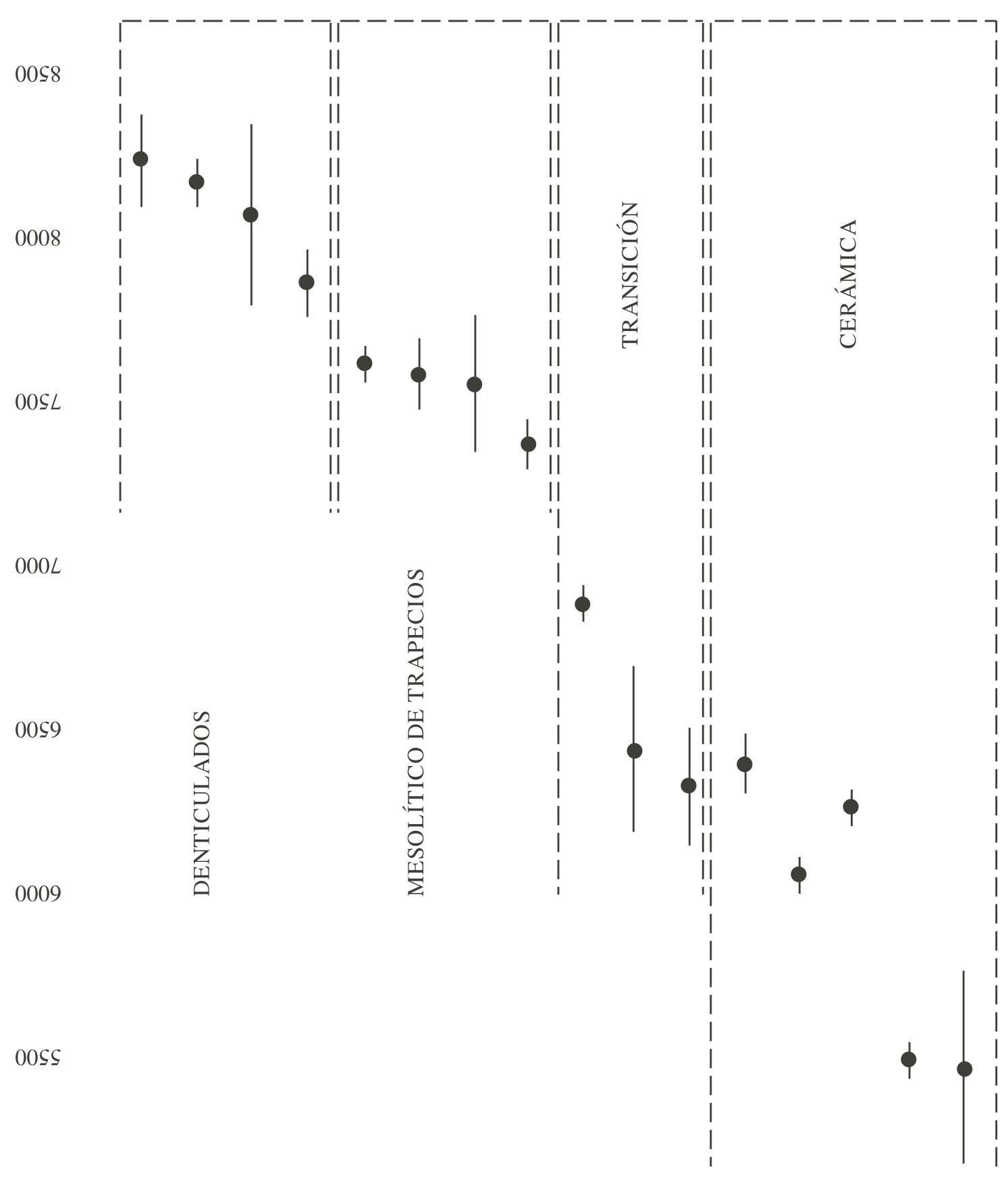

$000 S$

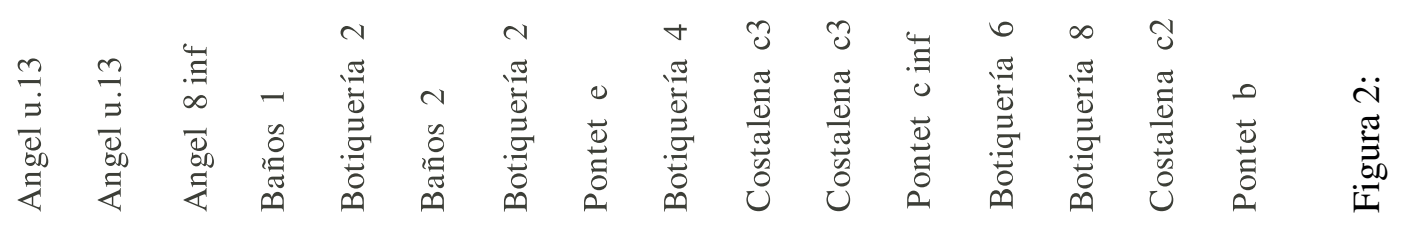

